\title{
Geotechnical modelling of the climate change impact on world heritage properties in Alexandria, Egypt
}

Sayed Hemeda ${ }^{1,2^{*}}$ (1)

\begin{abstract}
Alexandria is one of the Mediterranean UNESCO World Heritage sites at risk from coastal flooding and erosion due to sea-level rise. The city's position on the Mediterranean coast means it is especially vulnerable to rising sea levels. Alexandria is one of UNESCO sites in Egypt at risk from flooding. All the archaeological sites in the northern coast of Egypt are also said to be at risk from coastal erosion. The flood risk in Alexandria is expected to reach a tipping point by 2050. This research presents the numerical analysis of geotechnical and structural damage mechanism of Catacombs of Kom El-Shoqafa and El-Shatbi Necropolis; the sites have the lowest topography in Alexandria induced by the sea level rise and heavy rain due to the Climate Change, based on Finite Element PLAXIS Code. The purpose of the study was to investigate the behavior fully-saturated soft rock/ hard soil subjected to ground water intrusions. The main objective of this study is to very accurately record and analyze geotechnical problems and induced structural failure mechanisms that have been observed and accounted for in field, experimental and Numerical studies. The land area is also vulnerable to coastal flooding. It is widely expected that the numerical analysis of such geotechnical problems will contribute to the preservation of cultural heritage. The present research presents an attempt and experimental study to design a PLAXIS 2D FE model to simulate hard soil/hard rock problems, distortion and stress analysis of the complex structure of the catacombs. Plastic modeling or Mohr-Coulomb model was used in advanced soils during various stages of numerical analysis. Results are recorded and discussed regarding stress and volumetric behavior of soil/rocks. Groundwater infiltration into pores or fissures of rock and soil has a great influence on the engineering mechanical properties of rocks and soils.
\end{abstract}

Keywords: Climate Change, World heritage properties, Catacombs of Kom El-Shoqafa, El-Shatbi Necropolis, Numerical Analysis, Mitigation Strategy

\section{Introduction}

According to the United Nations Office for Disaster Risk Reduction, during the $1998-2017$ period, $5.3 \%$ of all global disasters originated from high temperatures, whereas droughts caused $4.8 \%$, severe storms $28.2 \%$, and hurricanes $43.4 \% .1$ In other words, $82 \%$ of natural disasters during this period were climate related. The

\footnotetext{
*Correspondence: Sayed.hemeda@cu.edu.eg; Sayed.hemeda@ejust.edu.eg ${ }^{1}$ Conservation Department, Faculty of Archaeology, Cairo University, Giza, Egypt

Full list of author information is available at the end of the article
}

2014 report by the Intergovernmental Panel on Climate Change (IPCC) clearly states that "Changes in many extreme weather and climate events have been observed since about 1950. Some of these changes have been linked to human influences, including a decrease in cold temperature extremes, an increase in warm temperature extremes, an increase in extreme high sea levels, and an increase in the number of heavy precipitation events in a number of regions" [1]. The IPCC believes that the influences of climate change will not be uniform across the globe but will rather vary among regions and that average global temperatures are expected to increase between
Springer Open

(c) The Author(s) 2021. This article is licensed under a Creative Commons Attribution 4.0 International License, which permits use, sharing, adaptation, distribution and reproduction in any medium or format, as long as you give appropriate credit to the original author(s) and the source, provide a link to the Creative Commons licence, and indicate if changes were made. The images or other third party material in this article are included in the article's Creative Commons licence, unless indicated otherwise in a credit line to the material. If material is not included in the article's Creative Commons licence and your intended use is not permitted by statutory regulation or exceeds the permitted use, you will need to obtain permission directly from the copyright holder. To view a copy of this licence, visit http://creativeco mmons.org/licenses/by/4.0/. The Creative Commons Public Domain Dedication waiver (http://creativecommons.org/publicdomain/ zero/1.0/) applies to the data made available in this article, unless otherwise stated in a credit line to the data. 

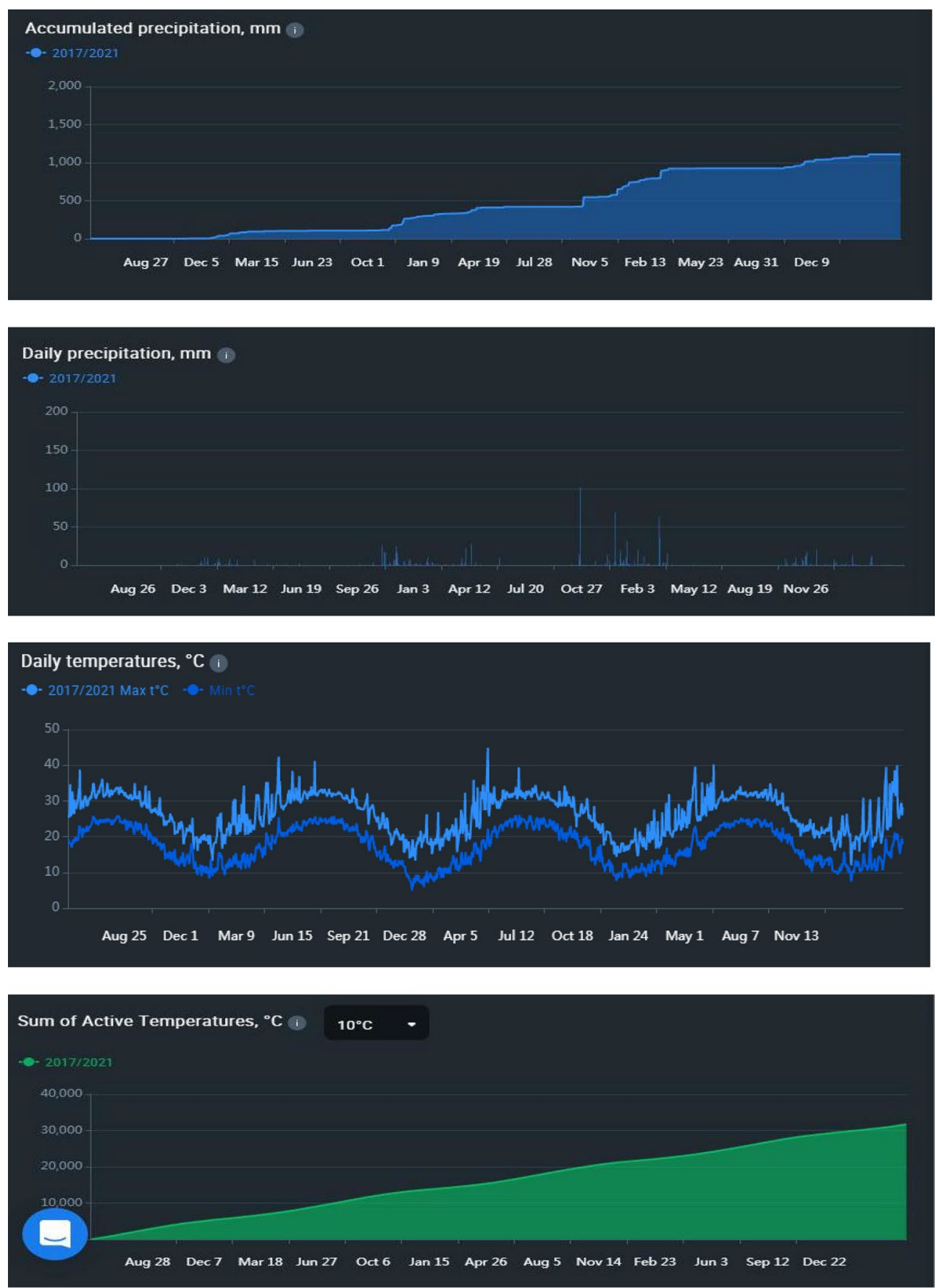

Fig. 1 Increasing of Temperature and Moisture in Alexandria during the last 5 years, from 2017 to 2021

$1.4{ }^{\circ} \mathrm{C}$ and $5.8{ }^{\circ} \mathrm{C}$ by 2100 , [2]. Figure 1 represents the Increasing of Temperature and Moisture in Alexandria during the last five years, from 2017 to 2021.
The coastal city of Alexandria in Egypt, which has survived invasions, fires and earthquakes since it was founded by Alexander the Great more than 2,000 years 


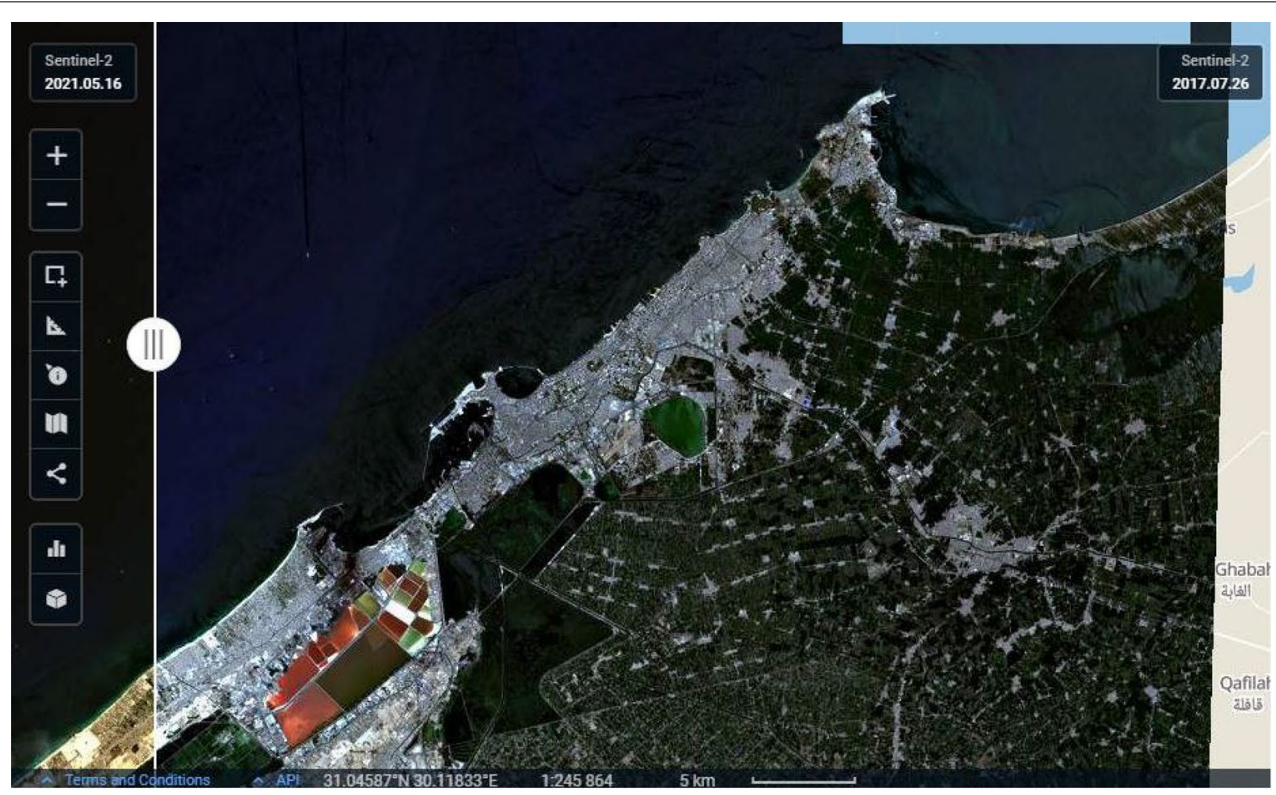

(a)

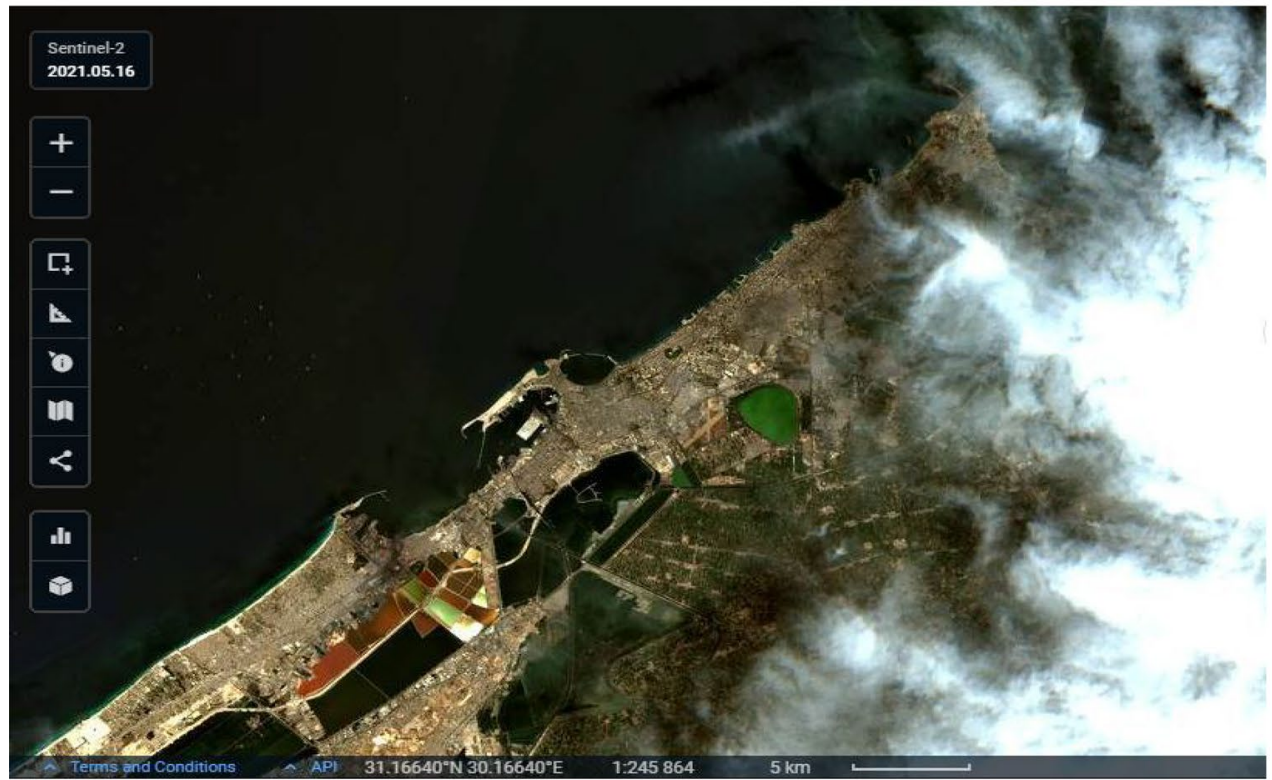

(b)

Fig. 2 EOS Landviewer satellite image of the shoreline of Alexandria city in a 26 July 2017 and $\mathbf{b}$ in 16 May 2021, and the shoreline erosion is obvious recently

ago, now, faces a new threat of climate change. Figure 2 represents the EOS Landviewer satellite image of the shoreline of Alexandria city in a) 26 July 2017 and b) in 16 May 202, and the shoreline erosion is obvious recently.
Sea level rise threatens to inundate archaeological sites, prompting authorities to erect concrete barriers in the sea to break the tide. A severe storm in 2015 


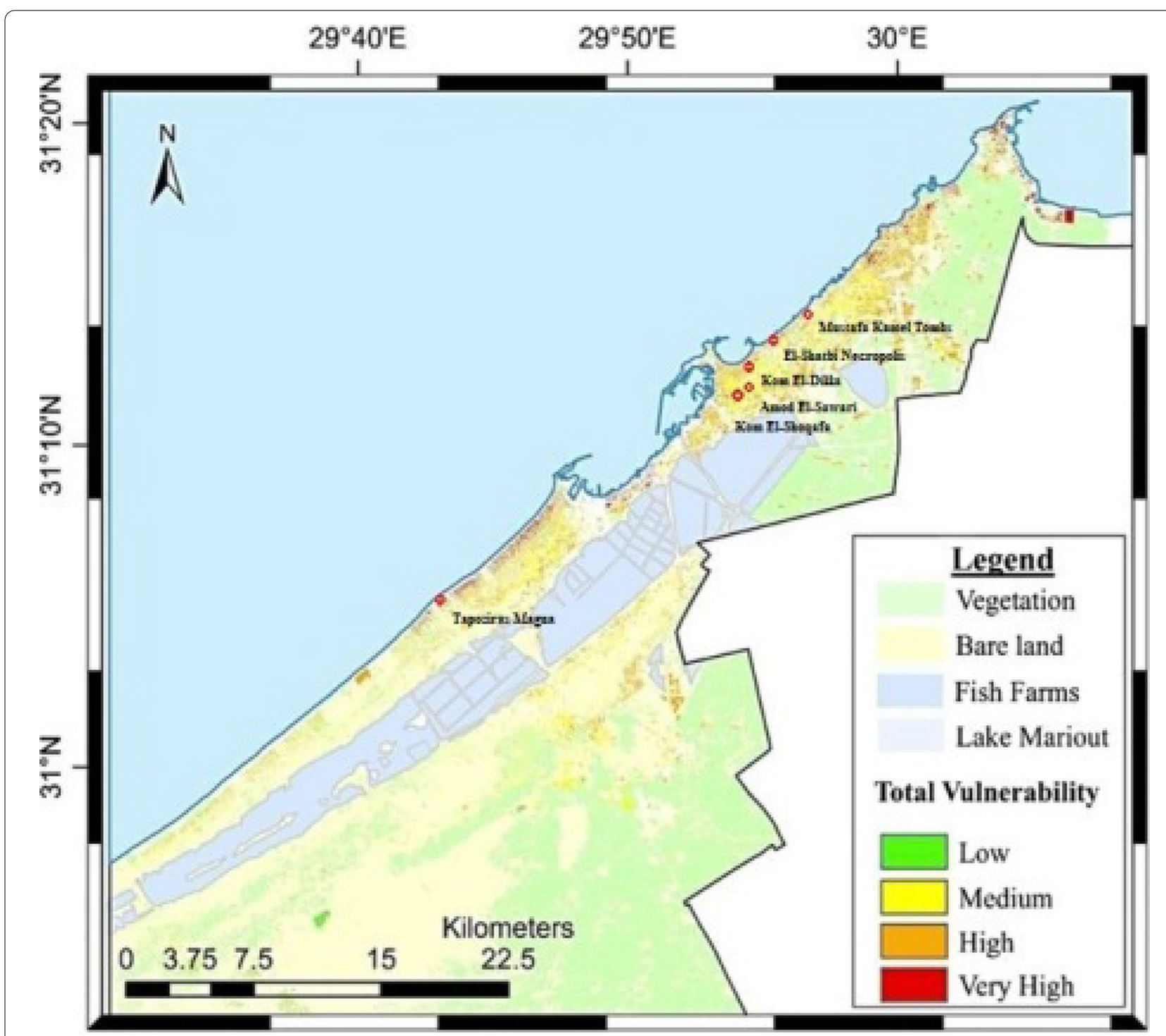

Fig. 3 Pluvial flooding Vulnerable map of Alexandria UNESCO world heritage properties

flooded large parts of the city, killing at least six people and the collapse of about twenty homes, see Fig. 3.

According to the Global Assessment Report on Disaster Risk Reduction (GAR), flash foods are the most widely distributed natural hazards in Egypt.

Alexandria, the country's second largest city, is surrounded on three sides by the Mediterranean and backed by a lake, making it uniquely vulnerable to sea level rise caused by global warming and melting polar ice caps.

In the late 1940's and 1950's, it was a haven for writers and artists who attracted wealthy Egyptian and foreign tourists for its beauty and charm. Today, more than $60 \mathrm{~km}$ (40 miles) of the waterfront makes it a prime summer destination for Egyptians, but many of its most famous beaches are already showing signs of erosion.

The United Nations' Intergovernmental Panel on Climate Change has warned that global sea levels could rise by 0.28 to $0.98 \mathrm{~m}$ (1-3 feet) by 2100 , with "serious repercussions for coastal cities, deltas and low-lying countries." 
Experts acknowledge that regional differences in sea level rise and its impacts remain poorly understood. But in Alexandria, a port city of more than 5 million people and about $40 \%$ of Egypt's industrial capacity, there are already signs of change.

Sea level changes are caused by several natural phenomenon; the three primary contributing ones are: ocean thermal expansion, glacial melt from Greenland and Antarctica-in addition to a smaller contribution from other ice sheets- and change in terrestrial storage. Among those, ocean thermal expansion has been expected to be the dominating factor behind the rise in sea level. However, new data on rates of deglaciation in Greenland and Antarctica suggest greater significance for glacial melt, and a possible revision of the upper bound estimate for sea level rise (SLR) in this century. It is predicted that, with global warming, global average sea levels may rise by between 7 and $36 \mathrm{~cm}$ by the 2050s, by between 9 and $69 \mathrm{~cm}$ by the $2080 \mathrm{~s}$ and $30-80 \mathrm{~cm}$ by 2100 . The majority of this change will occur due to the expansion of the warmer ocean water.

The Egyptian Ministry of Water Resources and Irrigation says that the sea level rose at an average rate of $1.8 \mathrm{~mm}$ per year until 1993. Over the next two decades, the water level rose to $2.1 \mathrm{~mm}$ per year, and since 2012 it reached $3.2 \mathrm{~mm}$ per year, which is enough to threaten building foundations.

The land, on which Alexandria is built, along with the surrounding Nile Delta, is sinking at roughly the same rate, in part due to upstream dams that prevent the regeneration of silt and the extraction of natural gas. This is expected to exacerbate the effects of sea level rise, with potentially dire consequences.

A 2018 study predicted that as many as 734 square kilometers (more than 283 square miles) of the Nile Delta could be submerged by 2050 and $2.660 \mathrm{~km}^{2}$ (more than 1.020 mile $^{2}$ ) by the end of the century, affecting 5.7 million people.

In El-Max neighborhood, hundreds of people were forced to leave their homes after severe floods in 2015 and October 2020, Fig. 4. The Ministry of Housing built nine housing complexes to house them after the area was declared unsafe.

The archeological sites in the city are those that have survived its turbulent history are truly threatened.

The Pharos Lighthouse, once among the tallest buildings ever built and one of the Seven Wonders of the Ancient World, was hit by an earthquake in the fourteenth century. The famous Library of Alexandria was completely burned down when Julius Caesar set fire to a hostile fleet in $48 \mathrm{BC}$.

But Citadel of Qaitbay, a medieval fortress built on the ruins of the lighthouse at the end of a narrow peninsula jutting out into the sea, still looms over the sprawling central port of the city, on the other side of the modern Library of Alexandria, a research center has opened. In 2002.

The castle is particularly vulnerable. Increasingly strong waves and currents pushed to the foundations, forcing authorities to install a long series of concrete sea barriers visible from the downtown waterfront, known as the Corniche.

Inland sites are also at risk, including the Catacombs of Kom al-Shuqafa and the Cemetery of Shatibi, the sites have the lowest terrain, dating back to the second century AD with architectural styles inspired by ancient Egypt. The catacombs and other sites such as the Shatibi cemetery were flooded in 2015, as shown in Figs. 5 and 6.

Prophet Daniel Street in the city center is one of the oldest streets in the world, and today it passes in front of a mosque, synagogue and St. Mark's Church, the seat of the Coptic Christian Patriarchate.

We realize that this street, which has survived for hundreds of years, could be underwater in the years to come, in our lives.

\section{"Every year the waves are stronger than they were in the previous year. The winters are harsher and the summers are hotter."}

Groundwater infiltration into pores or fissures of rock and soil has a great influence on the engineering mechanical properties of rocks and soil. For example, groundwater intrusion will deform rock and soil seepage, which will directly affect the stability and integrity of structures inside, buildings and foundations; The change of groundwater level will alter the effective stress field in soil/rocks, resulting in soil recovery or stabilization; Changing the groundwater level will also change the soil moisture content, which will also change the mechanical properties of the soil and cause the bearing capacity of the soil.

Rising groundwater levels due to sea level rise and heavy rains will inevitably lead to a decrease in the carrying capacity of sandy soils as catacombs are excavated. The bearing capacity of sandy soils under water saturation conditions is less than that of unsaturated soils, and the average reduction range is $26-25 \%,[3,4]$.

This study provides a comprehensive analysis of the safety of underground antiquities. The safety analysis not only includes failure analysis but the effect of groundwater level rise around underground structures on the differential settlement has been thoroughly investigated.

Since about 1975, a series of industrial and agricultural changes have led to a remarkable increase in the groundwater level in the city of Alexandria, especially Lake Mariout (400 $\mathrm{m}$ from the catacombs), which is the main source of this groundwater inside the catacombs 


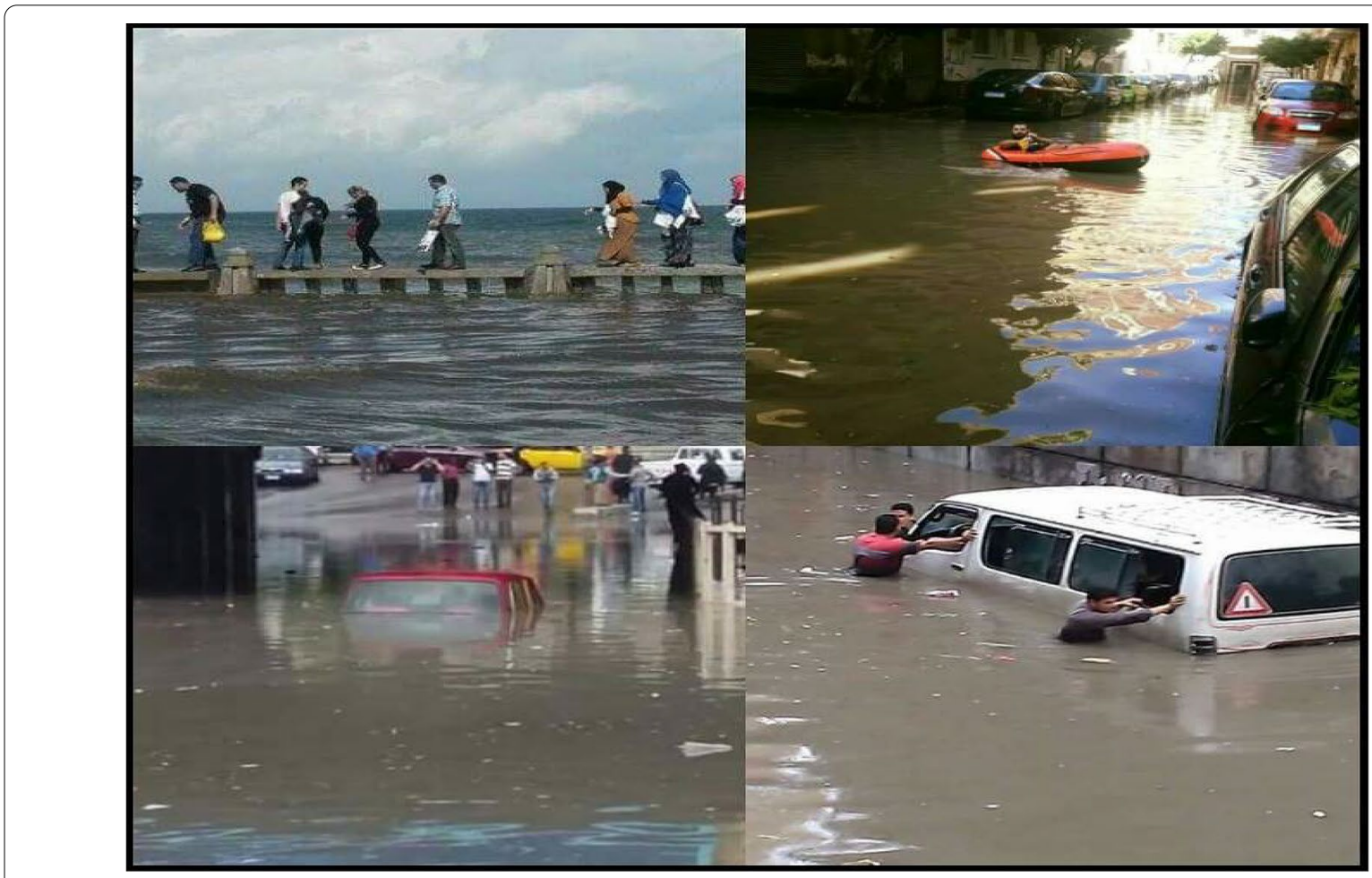

(a)
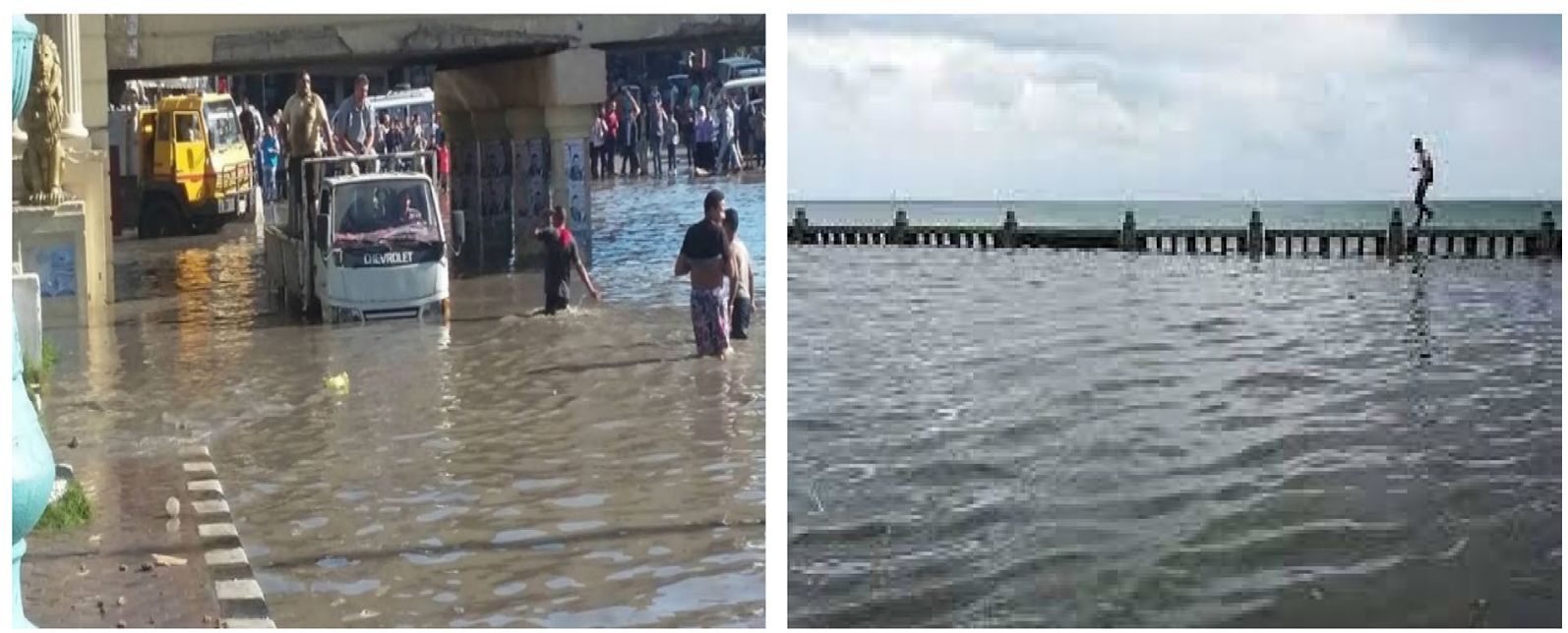

(b)

Fig. 4 a Alexandria pluvial foods in Oct. 15, 2015 and b Oct. 25, 2020, floodwater in the coastal and inside city of Alexandria

along with the heavy rains in the winter. The ice surface gradually reaches a height higher than the height of many underground "catacombs" monuments. As a result, some intense water leakage occurred at various locations within these underground structures.
The rise in groundwater levels can be in dramatic places due to subterranean development and this reduces the bearing capacity of rocks. The rise or fall of the water level may have dire consequences for the stability (structural effect) in terms of flooding of the subsurface parts. 

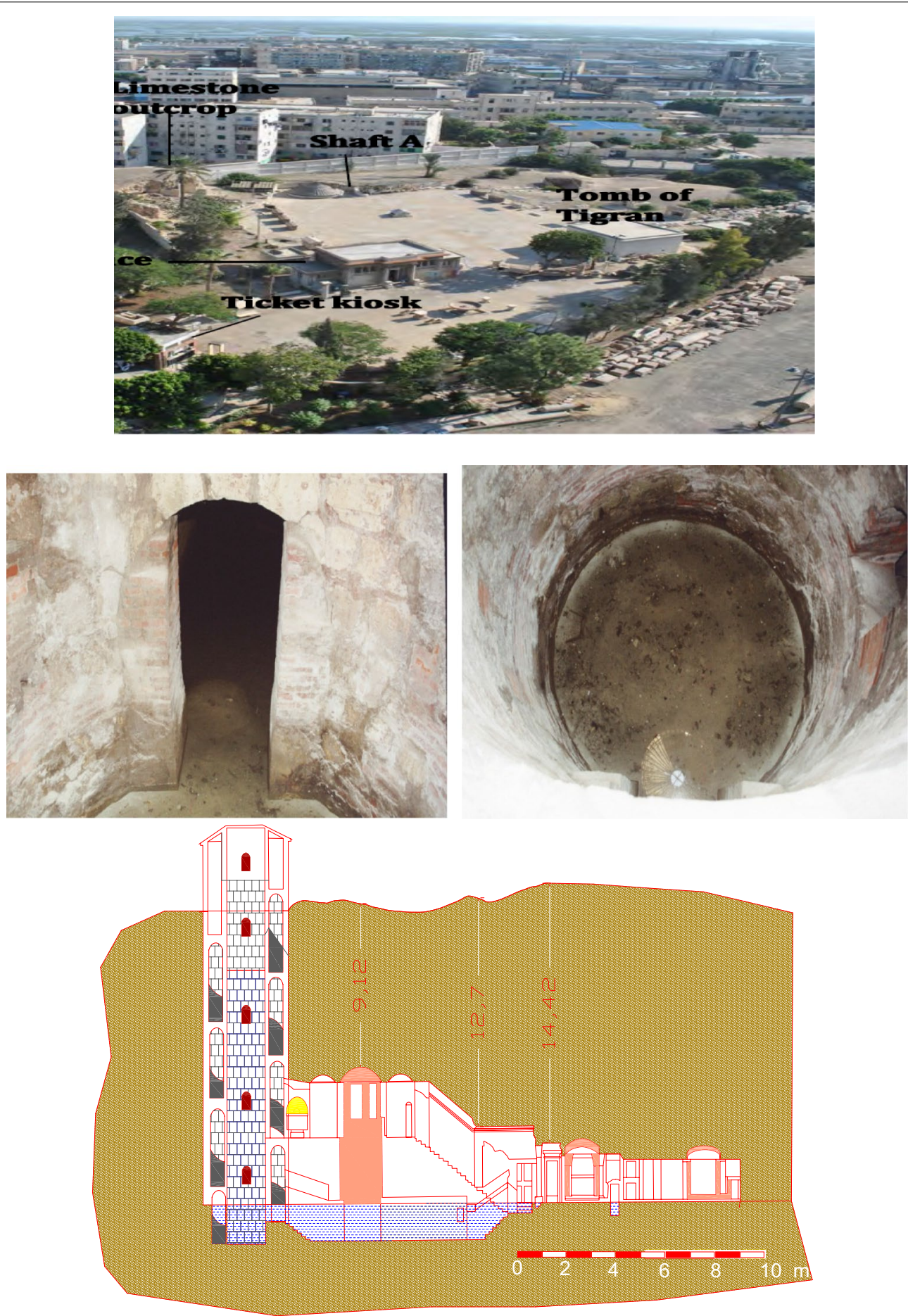

Fig. 5 Ground water intrusion inside the Catacombs of Kom El-Shoqafa in Alexandria

In some cases, changes in the groundwater level have had significant impacts on stability.

After the groundwater level decreased in 1995, the second level of the catacombs was opened to visitors but the lowest level is still submerged with some groundwater so far.

All the underground ruins (catacombs) in Alexandria suffer from a common problem: water leakage. Over 


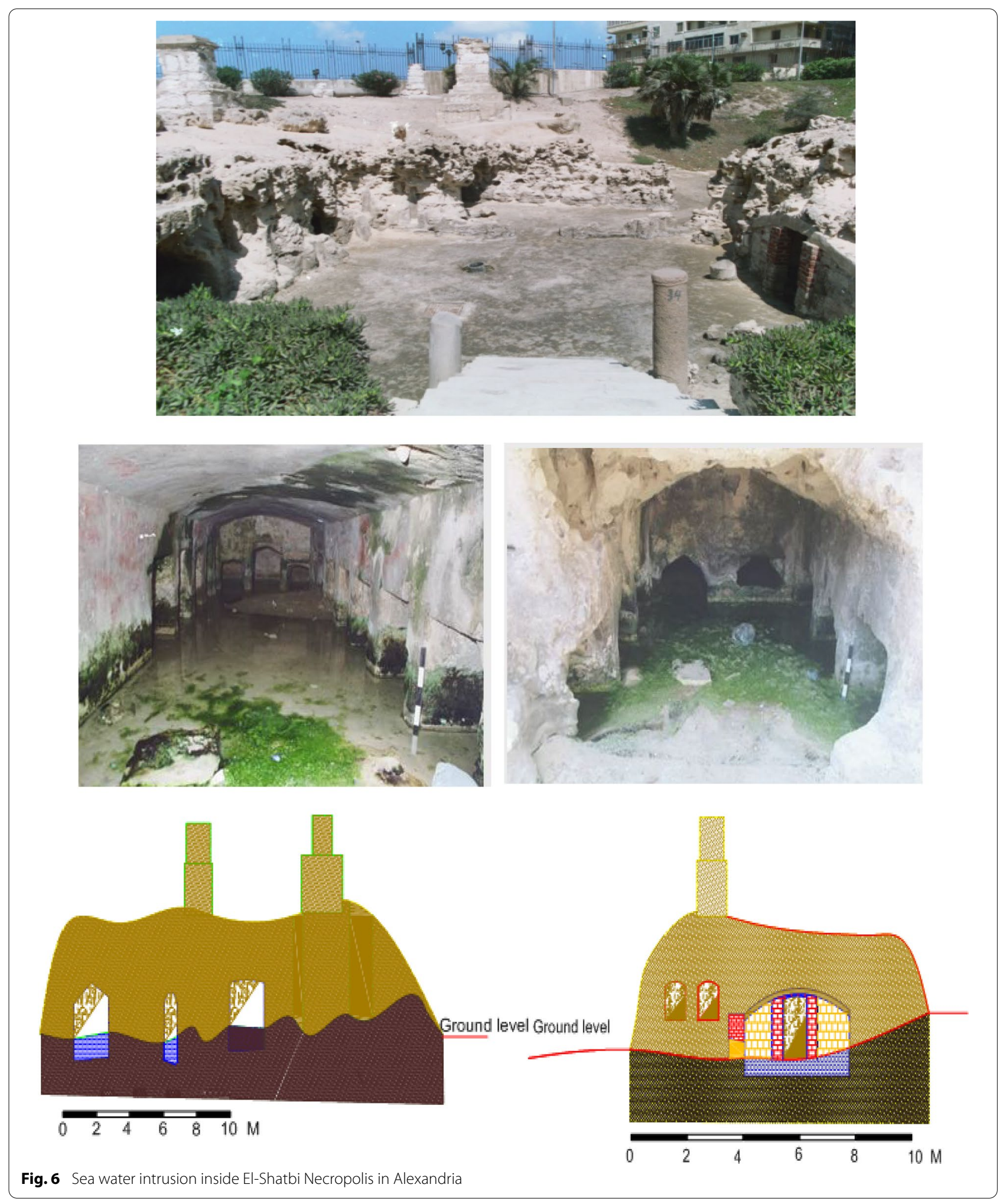


time, the infiltration may lead to increased humidity to excessive levels within the void created by the structure. This moisture and water seepage within the structure will cause cracking and peeling of rock surface layers and the formation of salt blooms and sub-fluorescences that can be dangerous to wall paint layers. The interaction of moisture with carbon dioxide may further degrade, resulting in the potential leakage of unwanted gases or dangerous chemicals from the surrounding soil.

The analysis of the integrity of surface and subterranean excavations in the shore cemetery not only includes failure analysis but also the effect of high water level around underground structures on the differential settlement was investigated.

Analysis of water samples collected from El Shatibi cemetery indicates that the water that floods all the cemetery grounds is sea water and sewage water from surrounding buildings. The rise in groundwater levels can be in dramatic places due to subterranean development and this reduces the bearing capacity of rocks. The rise or fall of the water level may have dire consequences for the stability (structural effect) in terms of flooding of the subsurface parts. In some cases, changes in the groundwater level have had significant impacts on stability.

Surface and underground excavations at El Shatbi suffer from a common problem of water leakage. Over time, the infiltration may lead to increased humidity to excessive levels within the void created by the structure. This moisture and water seepage within the structure will cause cracking and peeling of rock surface layers and the formation of salt blooms and sub-fluorescences that can be dangerous to wall paint layers. The interaction of moisture with carbon dioxide may further degrade, resulting in the potential leakage of unwanted gases or dangerous chemicals from the surrounding soil.

\section{Research methodolgy}

To determine the magnitude of stresses, analyze the deformation and settlement of the hard soil/ soft rock due to the ground water intrusion, where the catacombs are excavated, analytical models of geotechnical engineering are presented in detail. Geotechnical numerical modeling of complex soil/ structure problems requires advanced two and three-dimensional advanced soil models. PLAXIS 2D (PLAXIS v.b 2008) [5] was used to calculate the soil strength and bearing capacity reduction due to the impact of coastal flooding and erosion due to sea-level rise. PLAXIS 2D is a program produced and inquired about the geotechnical construction plan and recently used as part of the structural and geotechnical survey. The Mohr-Coulomb model is used for both static dynamic analyses. The code has a handy methodology for a programmed assembly engine, called Load Advancement, which we used here.

Foundational models are the bedrock not only for understanding the mechanical behavior of soils but also for implementing numerical predictions by means of the FE method, [6-8].

\section{Study areas}

The Kom al-Shoqafa cemeteries are located in the western cemetery of Alexandria. The facility was used as a burial chamber from the 2nd to the fourth centuries, before it was rediscovered in 1900 when a donkey accidentally fell into the entrance and consists of three levels cut through sandstone limestone, and the third level is now completely underwater. The catacombs contain a central pillar of six columns that opens from the vestibule. To the left is a funeral banquet hall where friends and family gather on stone couches covered in pillows, at the time of the burial and also for future memorial visits.

Table 1 Levels of pluvial flood [10]

\begin{tabular}{llll}
\hline Hazard Level & $\mathbf{0}$ & $\mathbf{1}$ & $\mathbf{2}$ \\
\hline Water Level $(\mathrm{m})$ & Less than 0.3 & From 0.3 to 0.6 & From 0.6 to 1.5 \\
Danger Level & No danger & Danger for some & Danger for most than 1.5 \\
\hline
\end{tabular}

Table 2 Expected rainfall rate regarding the different return period in Alexandria [10]

\begin{tabular}{lllllll}
\hline Return period & $\mathbf{2}$ years & $\mathbf{5}$ years & $\mathbf{1 0}$ years & $\mathbf{2 0}$ years & $\mathbf{5 0}$ years & $\mathbf{1 0 0}$ years \\
\hline Daily rainfall $(\mathrm{mm})$ & 24 & 41 & 58 & 76 & 102 & 125 \\
\hline
\end{tabular}


Table 3 The past flooding events in Alexandria [10]

\begin{tabular}{|c|c|c|c|c|c|}
\hline Date & Rainfall height & $\begin{array}{l}\text { Rainfall } \\
\text { duration }\end{array}$ & Economic loss & Human loss & Refs \\
\hline Dec 31, 1991 & $74 \mathrm{~mm}$ & N/A & $\mathrm{N} / \mathrm{A}$ & 80 died & Reliefweb (1996) \\
\hline January 26, 2004 & $\mathrm{~N} / \mathrm{A}$ & N/A & N/A & $\mathrm{N} / \mathrm{A}$ & CRED (2009) \\
\hline November 30,2010 & $180 \mathrm{~mm}$ & $12 \mathrm{~h}$ & $\mathrm{~N} / \mathrm{A}$ & 2500 family affected & World bank (2011) \\
\hline December 12, 2010 & $15 \mathrm{~mm}$ & $9 \mathrm{~h}$ & 28 building collapse & 11 injured 18 died & $\begin{array}{r}\text { World bank (2011), CRED (2009), the weather company } \\
\text { (2017), Crisis and disaster management in Alexandria }\end{array}$ \\
\hline November 14, 2011 & $12 \mathrm{~mm}$ & $9 \mathrm{~h}$ & $\mathrm{~N} / \mathrm{A}$ & $\mathrm{N} / \mathrm{A}$ & The weather company (2017) \\
\hline September 29, 2015 & $5 \mathrm{~mm}$ & $2 \mathrm{~h}$ & $\mathrm{~N} / \mathrm{A}$ & N/A & Williams and Ismail (2015) \\
\hline October 25, 2015 & $53 \mathrm{~mm}$ & $18 \mathrm{~h}$ & 9.7 million dollars & 16 injured 13 died & $\begin{array}{l}\text { CRED (2009), Zevenbergen et al. (2016), Xinhua (2015), } \\
\text { Flood list (2015) }\end{array}$ \\
\hline November 4, 2015 & $227 \mathrm{~mm}$ & $12 \mathrm{~h}$ & N/A & N/A & Zevenbergen et al. (2016) \\
\hline
\end{tabular}

El-Shatibi Cemetery is located in the old eastern quarter of Alexandria, overlooking the Mediterranean Sea. The Cemetery of El-Shatibi, which was rediscovered by chance in 1893 . The oldest cemetery in the city, may have served as a resting place for the deceased since the fourth. Century BC. These rock tombs are the oldest example of Alexandrian-style burials. Today, the graves of El Shatibi are located above the ground and exposed to the elements. But in its infancy, it was burial vaults. To reach them, visitors must descend several steps that lead to the main burial site.

\section{Pluvial flood hazard in Alexandria}

Climate change is assumed to lead to more rainfall events in Alexandria and increase the risk of heavy floods, and Tables 1 and 2 summarize the levels of heavy flooding and the expected rainfall rate in relation to the different return period in Alexandria. However, on November 4, 2015, Alexandria and some neighboring coastal cities experienced unexpected heavy rains of up to $227 \mathrm{~mm}$ felt in $12 \mathrm{~h}$, which is more aggressive than the 100-year return period record, causing severe flooding, see Fig. 2 and Table 3 summarizes the past severe flood events in Alexandria. He described this event as the worst floods that the city witnessed during the past few decades in terms of the number of people affected and economic losses, $[9,10]$.

Alexandria suffers from various urban problems that increase exposure to expected risks. The deterioration of sewage systems and the deterioration of their capacity are major problems. The capacity of the city's sewage network is about 1.6 million $\mathrm{m}^{3} /$ day, which is sufficient to drain the average rainfall of $26 \mathrm{~mm} /$ day. There are other factors that exacerbate the severity of the floods in Alexandria, such as high population density $\left(1600 / \mathrm{km}^{2}\right)$, urban expansion, and lack of vegetation cover, which increases water accumulation and inequality in distribution, [10].

\section{Sea level rise and storm surge}

Current (based on historical climate conditions and recent trends, generally over the past few decades) Sea levels have risen across the Mediterranean by an average of more than $3.1 \mathrm{~mm}$ each year since 1992, although records from further back indicate considerable local [11-14]. One array of tide gauges indicates that since 1990, Mediterranean Sea levels have risen at a rate $5-10 \%$ faster than the 20th- century mean rate. Measurements on the Egyptian coast indicate that sea level is continuously rising at a rate of 1.8 and $4.9 \mathrm{~mm}$ /year with an average of $3 \mathrm{~mm} /$ year [15]. The relative sea level shows an upward increasing trend as a result of land subsidence and eustatic sea level. In recent years (December 2003, December 2010, and January 2011), major storms have struck the Mediterranean coastline of Egypt and have produced_-during a short period_-a surge of up to about one meter above the mean sea level.

Future: 2030 (generally 2020-2049) Simple interpolation of a minimum and a maximum sea level rise scenario indicates that by 2030, the total, Mediterranean basin averaged sea level rise will be between 0.07 and $0.18 \mathrm{~m}$ [16]. One study used low $(0.07 \mathrm{~m})$, medium $(0.11 \mathrm{~m})$, and high $(0.25 \mathrm{~m})$ scenarios for sea level rise projections in the delta region in the year 2030 [17].

Future: 2050 (generally 2040-2059) Sea levels are projected to rise between 3 and $61 \mathrm{~cm}$ this century, depending upon local heat and salinity levels of the Mediterranean. Sea level rise projections in Egypt's delta are exacerbated by considerable land subsidence $(5.0 \mathrm{~cm} /$ year), and a tidal range of about $20 \mathrm{~cm} \mathrm{[16].} \mathrm{One} \mathrm{study}$ used low $(0.11 \mathrm{~m})$, medium $(0.20 \mathrm{~m})$, and high $(0.40 \mathrm{~m})$ 


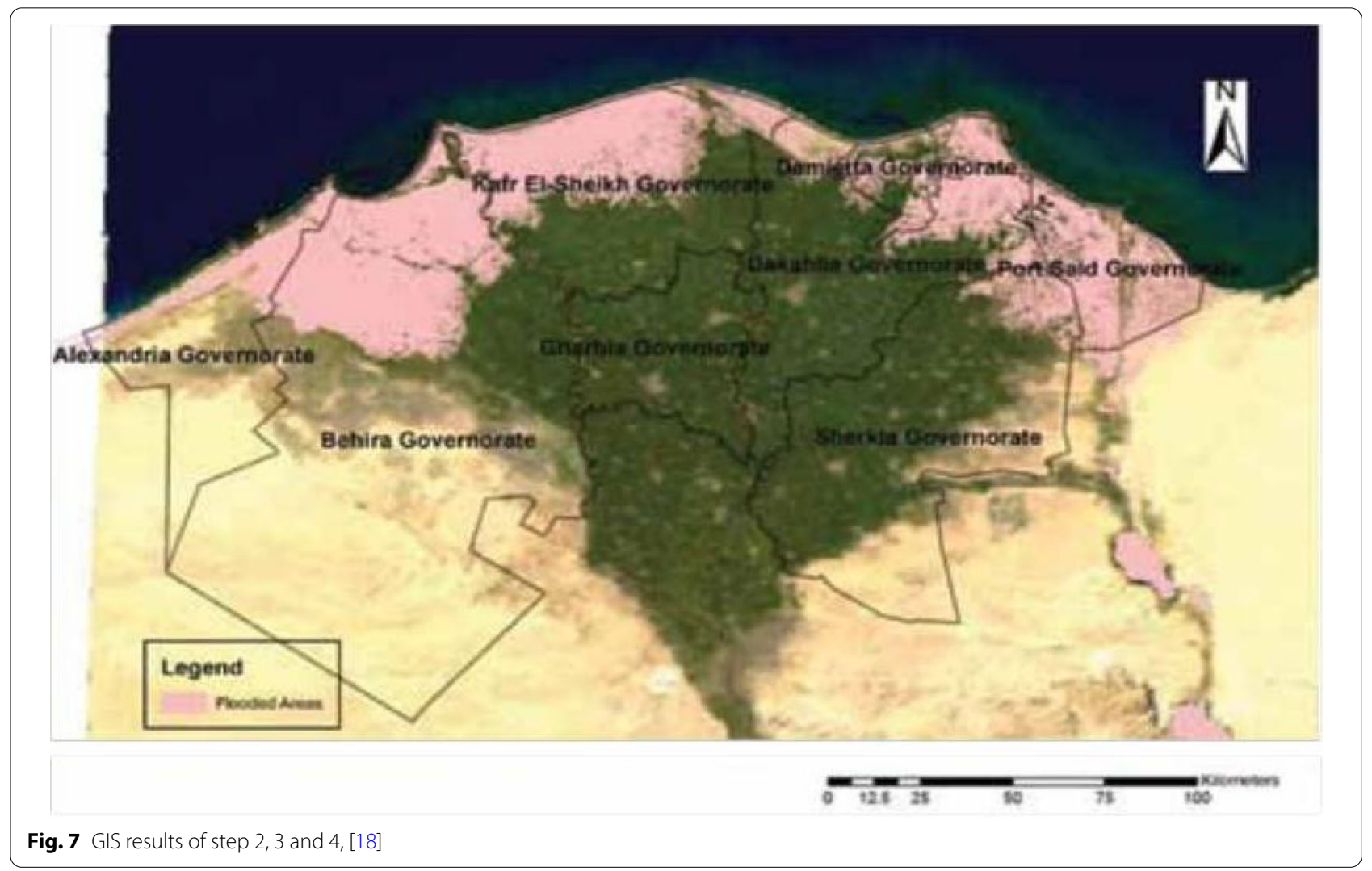

scenarios for midcentury sea level rise in the delta region [17]. Another study used low $(0.10 \mathrm{~m})$ and high $(0.26 \mathrm{~m})$ scenarios for sea level rise in the Mediterranean basin [16]. Particular risk areas in the Alexandria region are: Mandara and El Tarh (east of the city), and risk areas in the Nile Delta region are: The Manzala Lagoon barrier, east and west of the Rosetta City, Gamil, and the Tineh plain [15].

\section{Improving the estimation of sea level rise flooding impacts on the Nile delta and Alexandria using GIS and a flow routing model}

Various runs have been undertaken using the GIS and flow modeling techniques. The Shuttle Radar Topography Mission (SRTM) elevation data was used to represent to ground elevation in the delta. The SRTM resolution is $90 \mathrm{~m}$. The elevation data was not modified at the coastal defenses level assuming that they have deteriorated and do not offer enough protection. This was assumed to present the worst case scenario.

The steps described in Sect. 0 have been undertaken to estimate the extent of a sea level rise of $1 \mathrm{~m}$. It is clear that the extent is overestimated as there areas that are not connected to sea yet still flooded. Steps 2, 3 and 4 were therefore undertaken to correct this. A neighborhood function in GIS was used to remove noncontiguous flooded areas from the map. Figure 7 shows the results of steps 2, 3 and 4 in which all of the noncontiguous flooded areas was removed from the map. This is quite clear in the Behira governorate where the flooded area in the south was removed. Although steps 2, 3 and 4 shows a significant improvement over step1, there were still other areas that are not going to be flooded along the Nile and Suez canal due to the existence of hydraulic structures along the water way.

The TUFLOW model was used to estimate the flood extents due to sea level rise in the Nile Delta and Alexandria. The results of the TUFLOW model show a significant reduction in the estimated flood extent. The area flooded was estimated to be $2841 \mathrm{~km}^{2}$ including water body areas and $1166 \mathrm{~km}^{2}$ excluding. Figure 8 represented Sea level rise projections at Alexandria by 2100 for two scenarios with the amount of rise in meters indicated (mild $=1 \mathrm{~m}$; extreme $=3 \mathrm{~m}$ ). Percentage and total population displacement indicated bottom right. The SLR scenarios used in this study are based on the forecasts from Climate Central-Coastal Risk Screening Tool, [18]. 


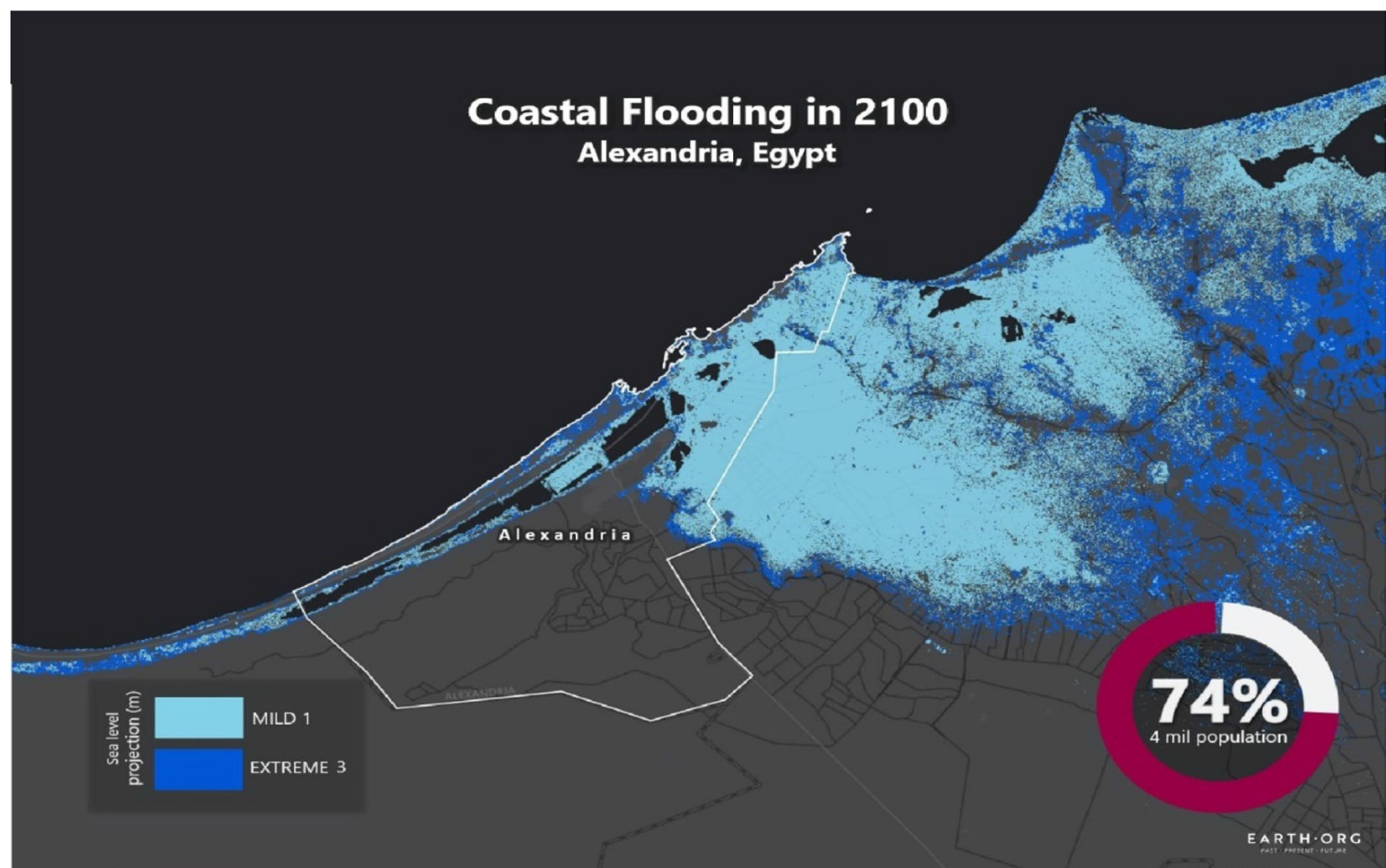

Fig. 8 Sea level rise projections by 2100 for two scenarios with the amount of rise in meters indicated (mild = $1 \mathrm{~m}$; extreme $=3 \mathrm{~m}$ ). Percentage and total population displacement indicated bottom right. The SLR scenarios used in this study are based on the forecasts from Climate Central_ Coastal Risk Screening Tool

\section{State of preservation}

The archaeological site in Alexandria exhibits complex geotechnical conditions. The geotechnical problems of this site are related to the stability of soft rocks. The mass and the action of groundwater, rocks can be considered as weak rocks consisting of low strength, sound materials (solid material), and weak in the sense that due to structural weakness (shear zones, faults); the mass of rocks behaves in a weak manner. Either way, these rocks pose special problems for engineering. Stability problems occur, in the first case, where the stress at the site and the stress created are greater than the intrinsic rock strength. In the second case, the problems are related to the weakness of the trend, [19-21].

We can see in the rock mass, almost vertical incisions are developed in which open joints, fractures and fissures intersect. This is then subjected to weathering and erosion processes. Weak areas were developed on the rock mass as favorable conditions were created to separate the rock masses causing large-scale downfall of the rocks. Surface fossils tend to be less stable because pressures at the site are lower, rocks are affected by weathering as shown in Table 4 the engineering properties of the rock masses where the catacombs are excavated now are less than the ASTM standard requirements, and water is a more active factor. The transverse stress of continuous flow around a carefully drilled underground hole tends to hold the blocks in place in the wall and ceiling, while little or no surface traction acts on the faces of the blocks on the surface where the transverse stress is usually small.

The surface excavations at the El-Shatibi cemetery also include weathered rocks whose strength may be much lower than that of intact rocks and which will contain many of the more important faults. Some of the weaker rocks will continue to be degraded by disturbances during construction and subsequently under the influence of water and chemical reactions in warm and humid climates.

In general, the rock mass presents the phenomena of change and decomposition of visible materials above all in anomalous levels and in relation to the phases of interruption. One of the factors that have contributed to the modification of the properties of the mass and that it continues to function, the primary factor is water in all its forms, it exerts pressures determined by its free presence in the interruption and pressure in the pores of the filler material. From the interruptions themselves; such problems increase in conditions of thermal change. 


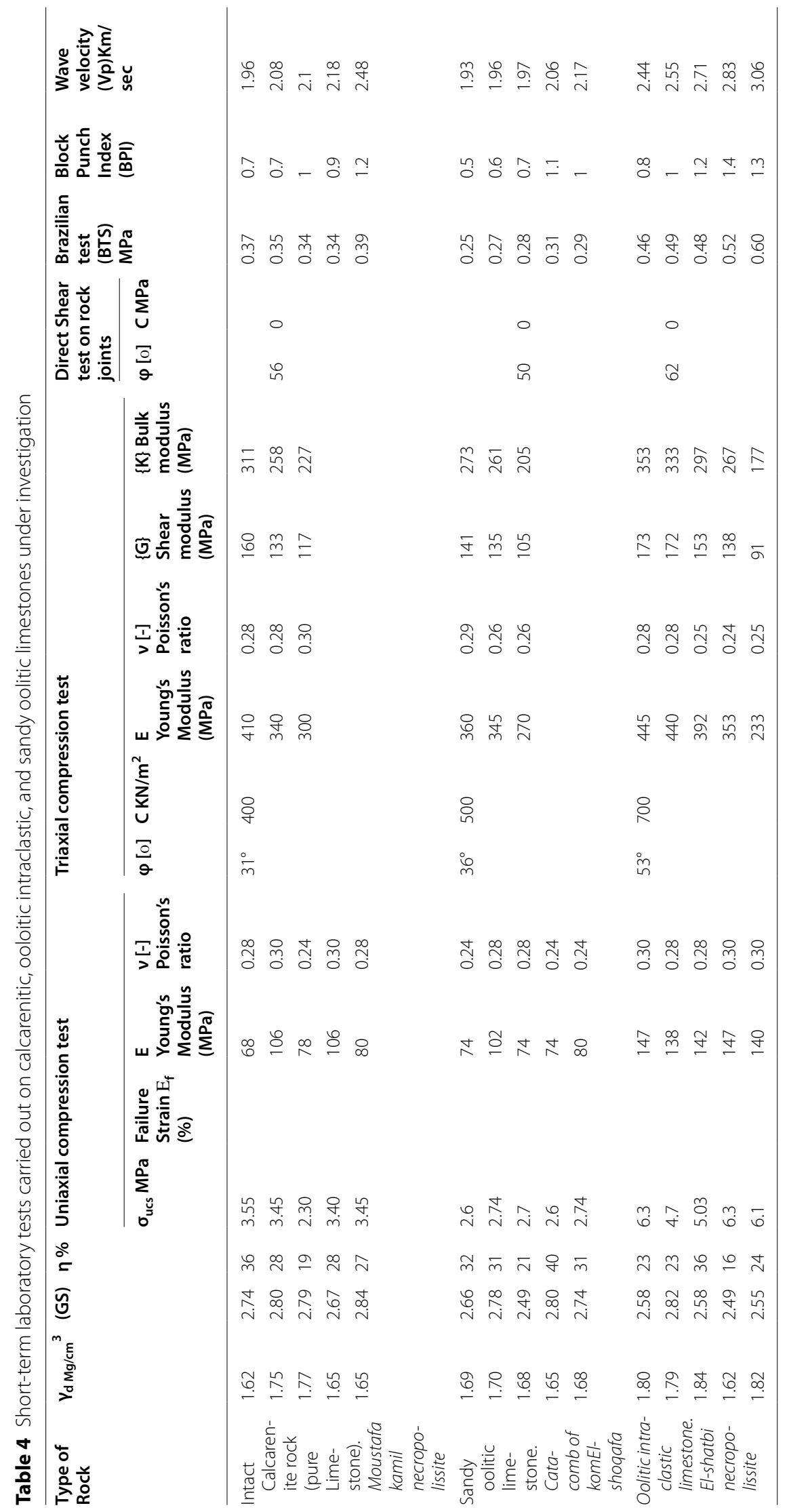


The presence of conduction stages, of different orientations, determines the subdivision of the rock mass into prismatic bodies of variable size in some cases this discontinuation stage is filled with materials with weak mechanical strength which produce deformation processes that tend to persist with increasing the phenomenon of decompression between the crack walls and reducing the internal bonds of rocks.

In such geotectonic conditions, erosion phenomena are included due to the effect of wind currents and actions of moisture/salts, the effect of meteoric waters, which chemically attack the calcareous components of the rocks and the consequent degradation of the mechanical property of the rock itself.

These sites represent intense weathering indicative of the scaling of the rock surface. Breakdown of building materials, an intense rock meal. The moist rock surfaces in particular can be observed for the semi-protected parts of excavation and severe weathering in the form of honeycomb, white salt bloom and yellowish-brown staining of iron in many parts. Structural damage is represented by cracking of ceilings, decay of the surface of the rocks, partial collapse of some parts of roofs and walls, peeling of rocks in particular in the ceiling of narrow entrances and tunnels, severe erosion in the deepest parts, and warping. In some parts, deep erosion in the lower levels of these tunnels and collective waste of their roofs and the walls of their corridors. Cracks of irregular shape. Some parts show severe breakdown, [22, 23].

The two processes working in earnest in these locations are groundwater and salt weathering in the field of diagnostic and laboratory indications, and humidification and drying associated with dielectric heating that is prevalent in semi-arid regions and sometimes in arid regions.

The rise in groundwater level can be in dramatic places due to subterranean development, the rise or fall of the water level may have disastrous consequences for the stability (structural effect) in terms of flooding of the subterranean parts. Landslides and other geological hazards, land subsidence or non-structural impacts that accompany material degradation through physical (temperature and moisture expansion) and chemical (air pollution, etc.) erosion. As a result of the modification of the groundwater system, several failures were observed in the structure of the grave.

\section{Numerical analysis results and discussion Catacombs of Kom El- Shoqafa}

Figure 9 represents the deformed finite element mesh and boundary conditions used for the numerical analyses of the soft rock excavations of Catacombs of Kom El-Shoqafa in underground water conditions (the underground water level is 3.9 to $4.5 \mathrm{~m}$ below the first floor of the Catacombs, the real state, a typical cross section_1).

The results from the preliminary static analysis indicate that the peak total displacements for the Catacombs complex is $2 \mathrm{~mm}$ in underground water conditions, while it was $1.13 \mathrm{~mm}$ in the initial dry conditions (Initial model). Figure 10a represents the peak horizontal displacements $(\mathrm{Ux})$ is $374.33^{*} 10^{-6} \mathrm{~m}$. Figure $10 \mathrm{~b}$ represents the peak vertical displacements (Uy) $2.00 * 10^{-3} \mathrm{~m}$ inside the Catacombs in the underground water conditions. Figure 11a represents the peak total displacement was 1.13 $* 10^{-3} \mathrm{~m}$ in the initial model, While it is $2.00 * 10^{-3} \mathrm{~m}$ in underground water conditions, as shown in Fig. $11 \mathrm{~b}$.

Some supporting rock piers are under relatively high compression stresses where the calculated peak effective principal compressive stress is $-1.42 * 10^{3} \mathrm{kN} / \mathrm{m}^{2}$ for the pier_1. Figure $12 \mathrm{a}$ represents the vertical peak effective compressive stress which is $-1.42 * 10^{3} \mathrm{kN} / \mathrm{m}^{2}$ in the initial model; Fig. 12b represents the same value in the underground water conditions, $\mathrm{n}$ static analysis. The effective compressive stresses on the top of rock piers increased obviously after rising of underground water level see Figs. 13 and 14. Figure 13 represents the effective compressive stresses distribution through the supporting rock piers_1 (a) in the initial (dry) model. (b) In underground water conditions.

Figure 14 represents the effective compressive stresses distribution through the supporting rock piers_2 (a) in the initial (dry) model. (b) In underground water conditions. The effective compressive stresses on the top of rock piers increased obviously after raising of underground water level.

The total strains (Peak principal strain) is $-67.11 * 10^{-}$ ${ }^{3} \%$ in underground water conditions, while it was -66 . $99 * 10^{-3} \%$ in the initial dry model, Fig. 15 presents the total strains. (Peak principal strain) is $-67.11^{*} 10^{-3} \%$ ), with underground water, while it was $-66.89 * 10^{-3} \%$ in the initial dry model. Figure 16 Vertical strains (Eps-yy). Peak vertical strain, peak (Eps-yy) $-52.26 * 10^{-3} \%$, and the peak horizontal strain $-31.99^{*} 10^{-3} \%$, underground water conditions while it was $-31.99^{*} 10^{-3} \%$ in the initial model. Figure 17 represents the extreme active pore pressure is $-458.69 \mathrm{kN} / \mathrm{m}^{2}$. The evaluation of a global safety factor of the construction processes is shown in Fig. 18.

\section{El-Shatibi necropolis}

Figure 19 presents the deformed finite element mesh and boundary conditions used for the numerical analyses of the soft rock excavations of El-Shatibi Necropolis in underground water conditions (the underground water level is $60 \mathrm{~cm}$ above the original ground level of the main tomb, the real state, and a typical cross section_1). Figure 19a represents the deformed mesh and boundary 


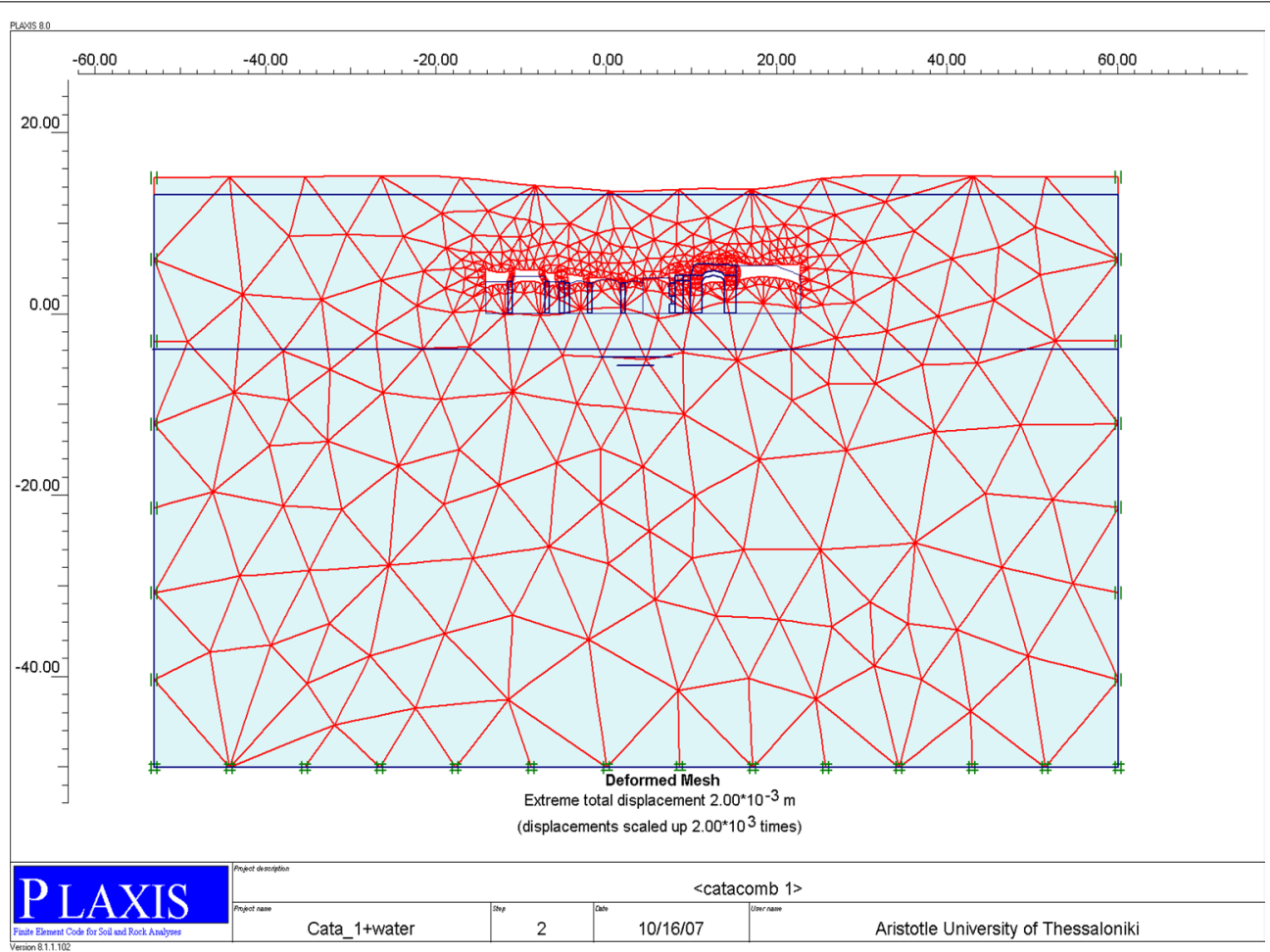

(a)

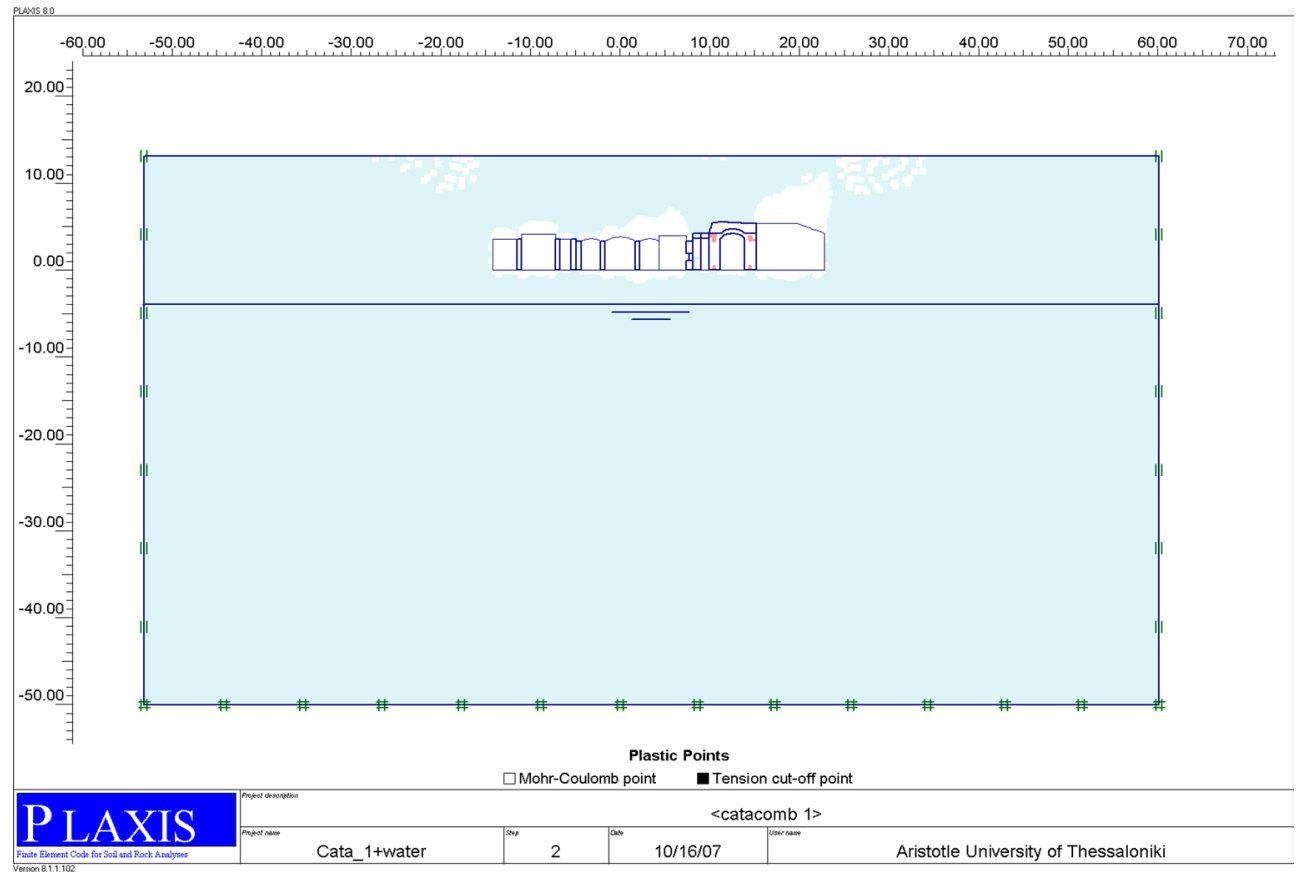

(b)

Fig. 9 a Deformed mesh and boundary conditions. b Plastic points distribution. Static analysis. Underground water conditions 

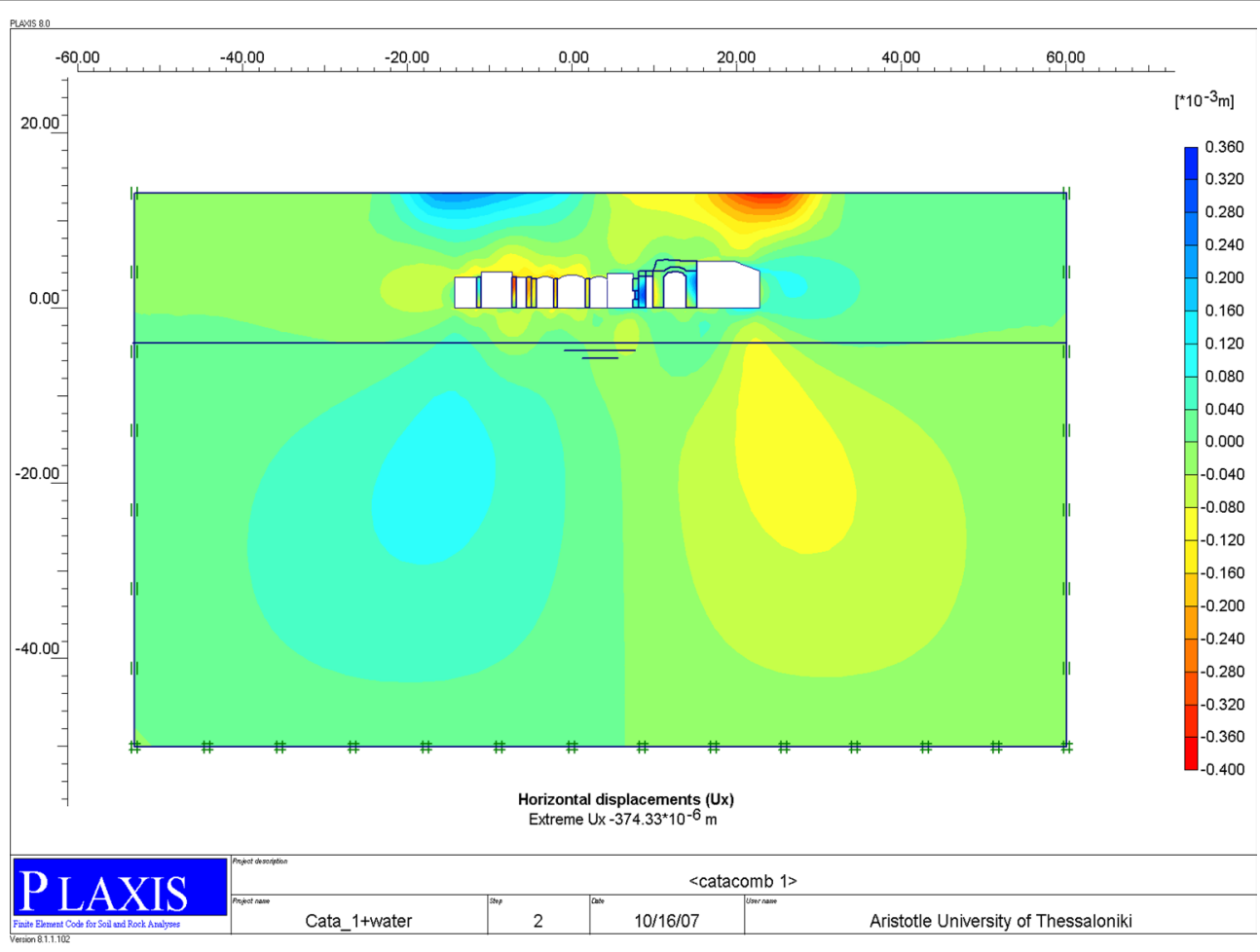

(a)

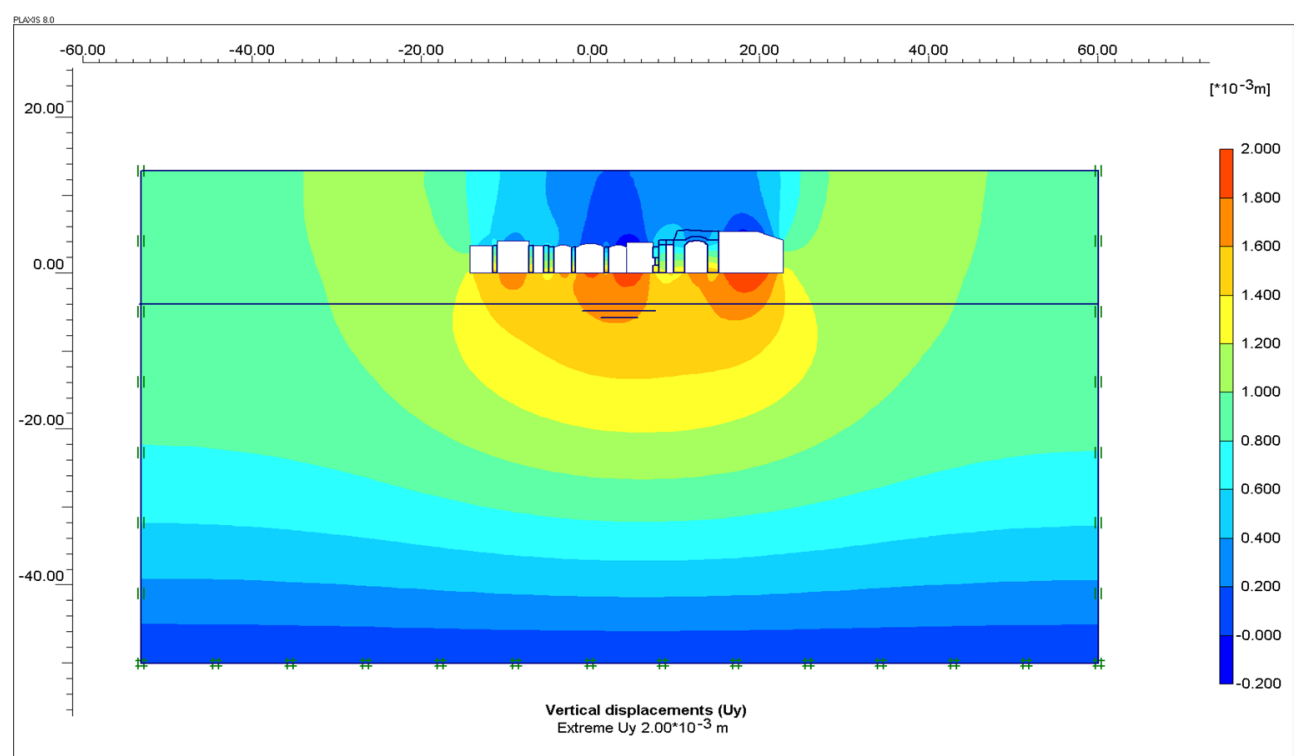

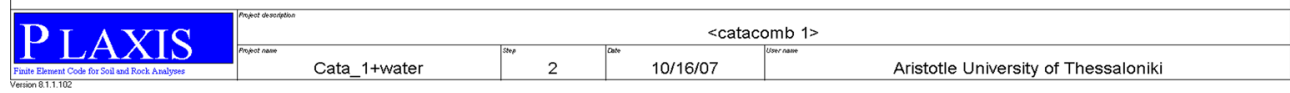

(b)

Fig. 10 a Peak horizontal displacements $U x=374.33^{*} 10^{-6} \mathrm{~m}$. b Peak vertical displacements $U y=2.00^{*} 10^{-3} \mathrm{~m}$ inside the Catacombs. Static analysis. Underground water conditions 


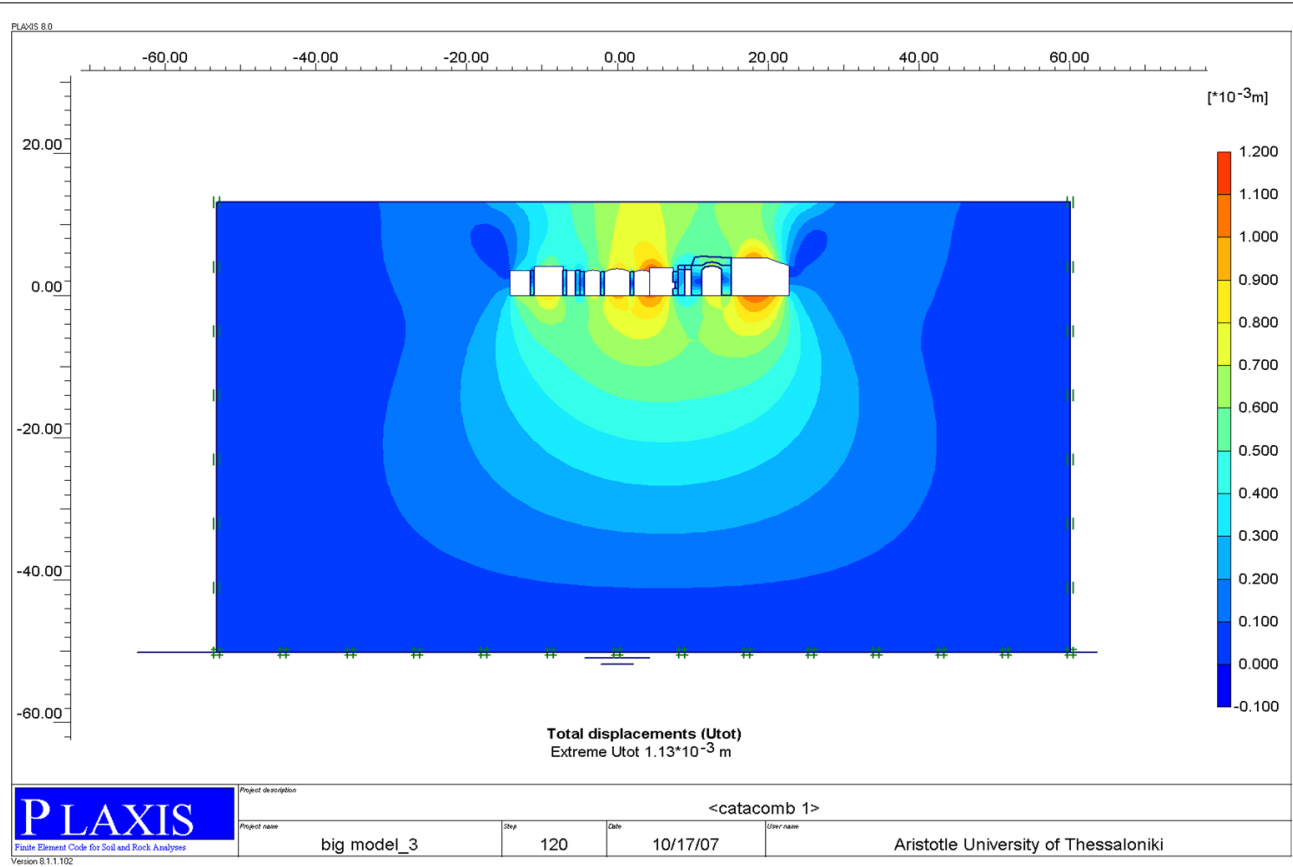

(a)

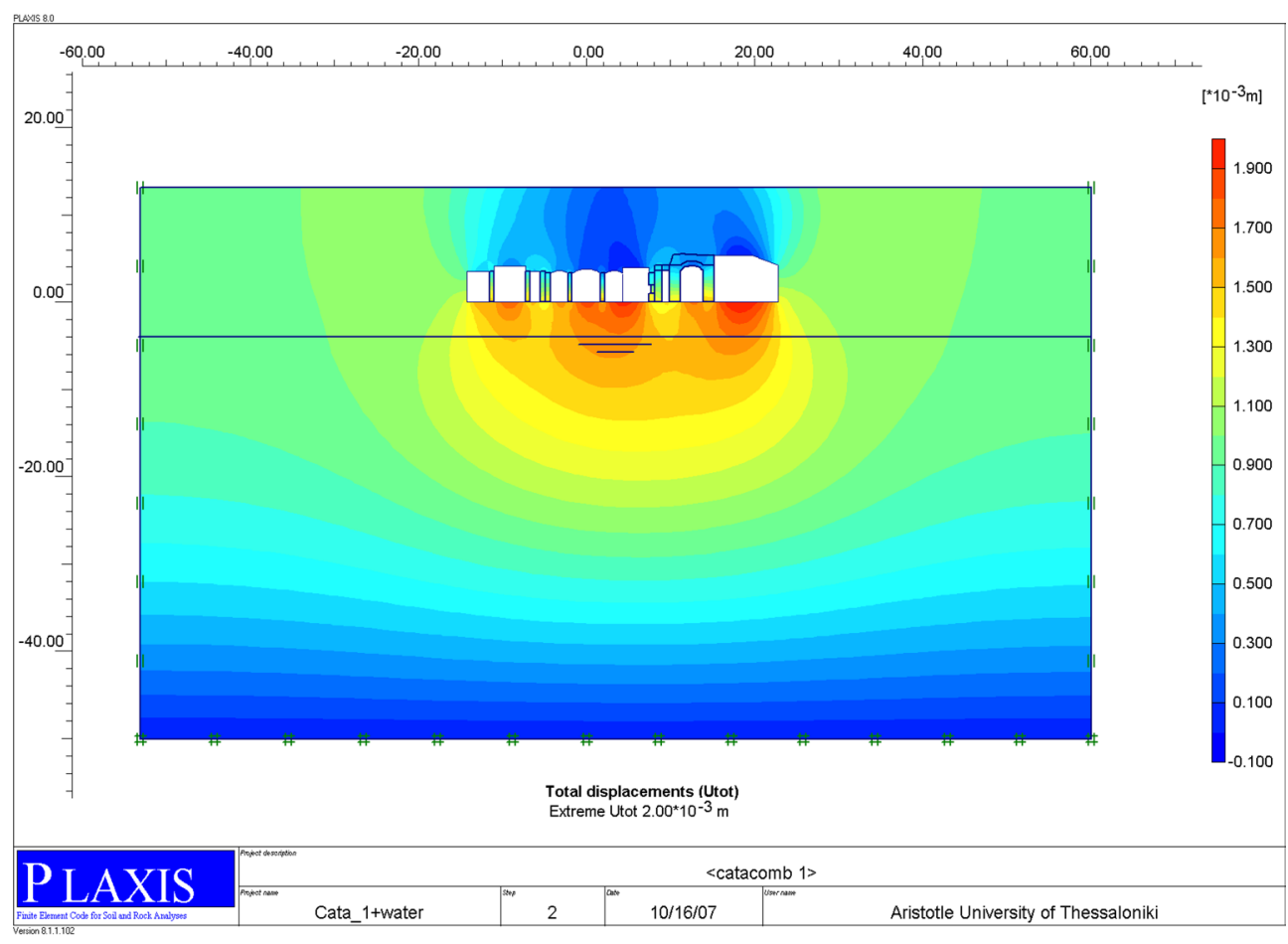

(b)

Fig. 11 a Peak Total displacement $=1.13 * 10^{-3}$ in the initial model, $\mathbf{b}$ While it is $2.00^{*} 10^{-3}$ in underground water conditions

conditions. (b) Plastic points distribution, static analysis in underground water conditions.

The results from the preliminary static analysis indicate that the peak total displacements for El-Shatibi complex in underground water conditions is $660.38^{*} 10^{-6} \mathrm{~m}$, while it was $86.64 * 10^{-6} \mathrm{~m}$ in the initial dry conditions (initial model). Figure 20a represents the Peak horizontal displacements (Ux) is $-49.07 * 10^{-6} \mathrm{~m}$. (b) Peak vertical 


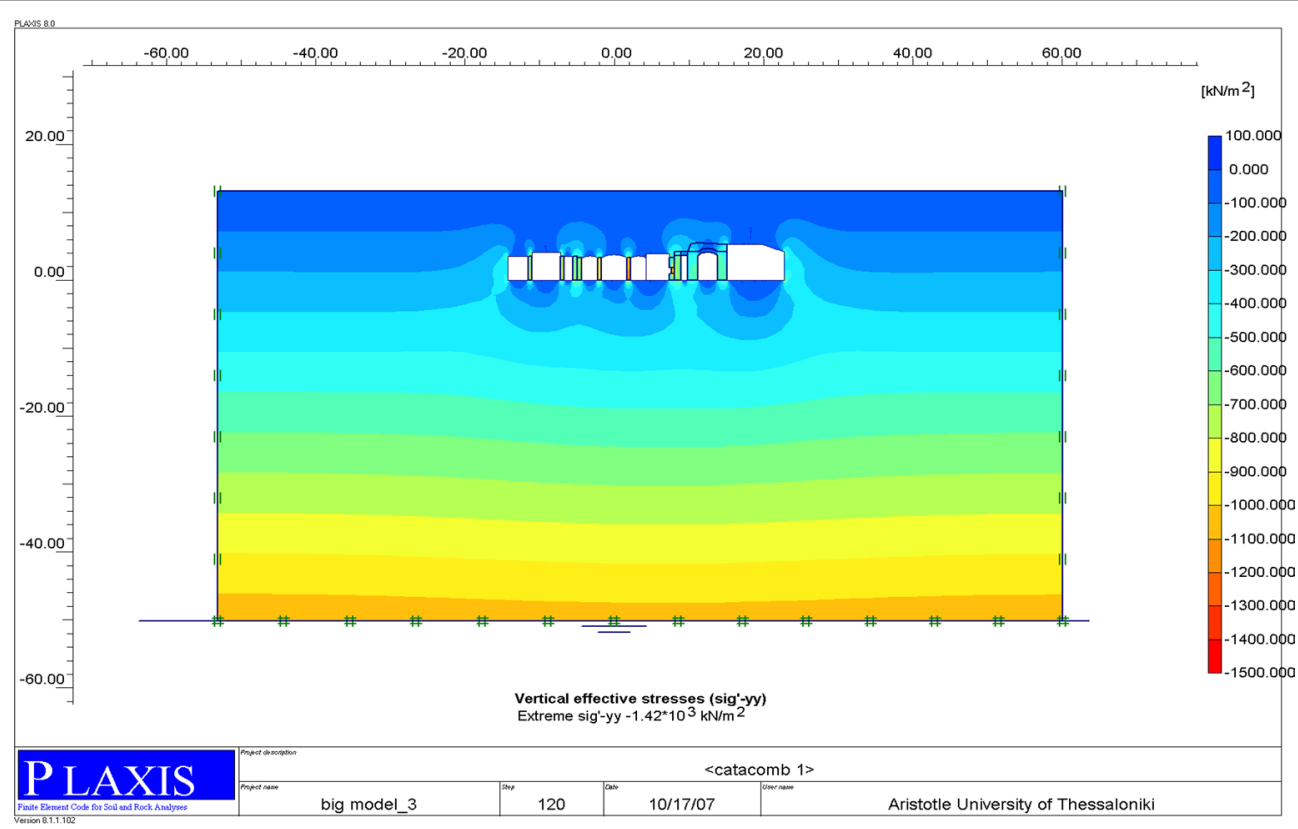

(a)

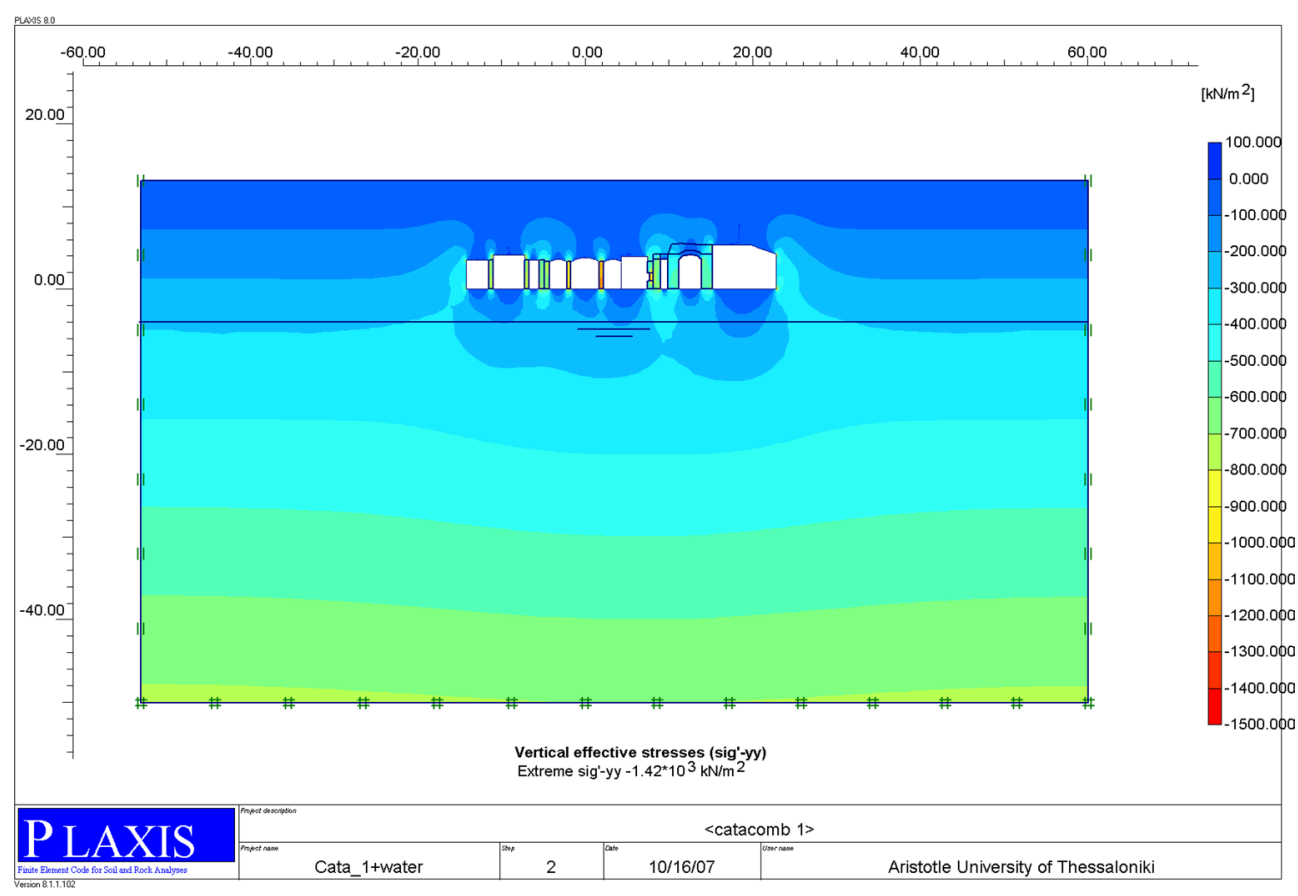

(b)

Fig. 12 a Vertical peak effective compressive stresses $=-1.42^{*} 10^{3} \mathrm{kN} / \mathrm{m}^{2}$ in the initial model, $\mathbf{b}$ the same value in the underground water conditions. Static analysis

displacements (Uy) is $660.18^{*} 10^{-6} \mathrm{~m}$ inside the excavations in underground water conditions.
Figure 21a represents that the peak total displacement was $86.64{ }^{*} 10^{-6} \mathrm{~m}$ in the initial dry model, while it is 


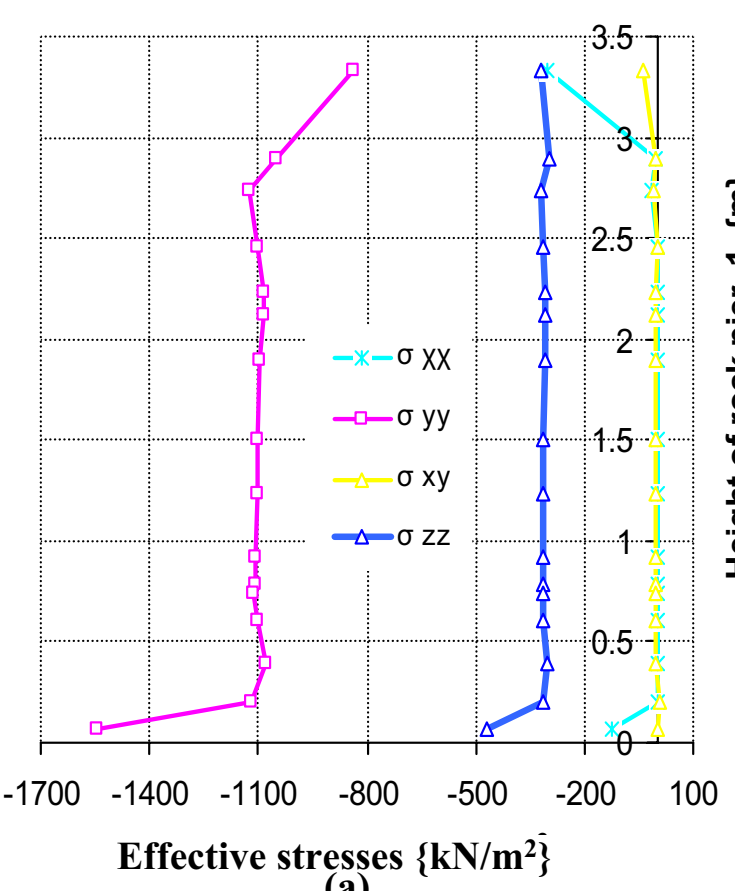

(a)

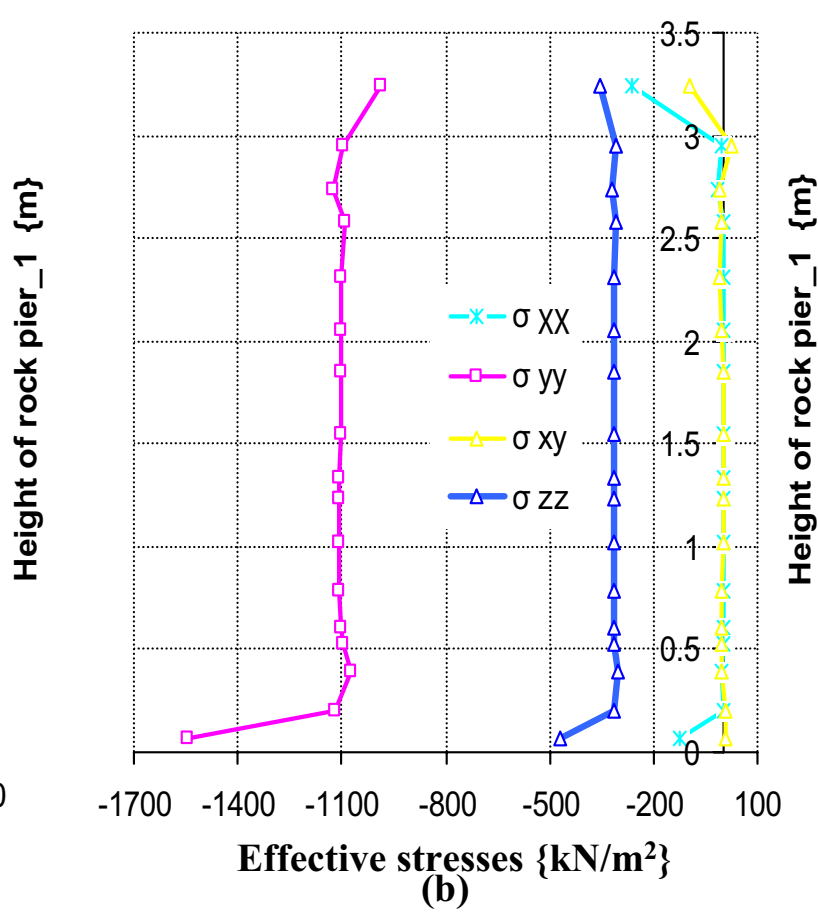

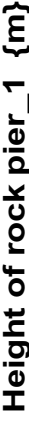

Fig. 13 Effective compressive stresses distribution through the supporting rock piers_1 a Initial model. b In underground water conditions. Static analysis

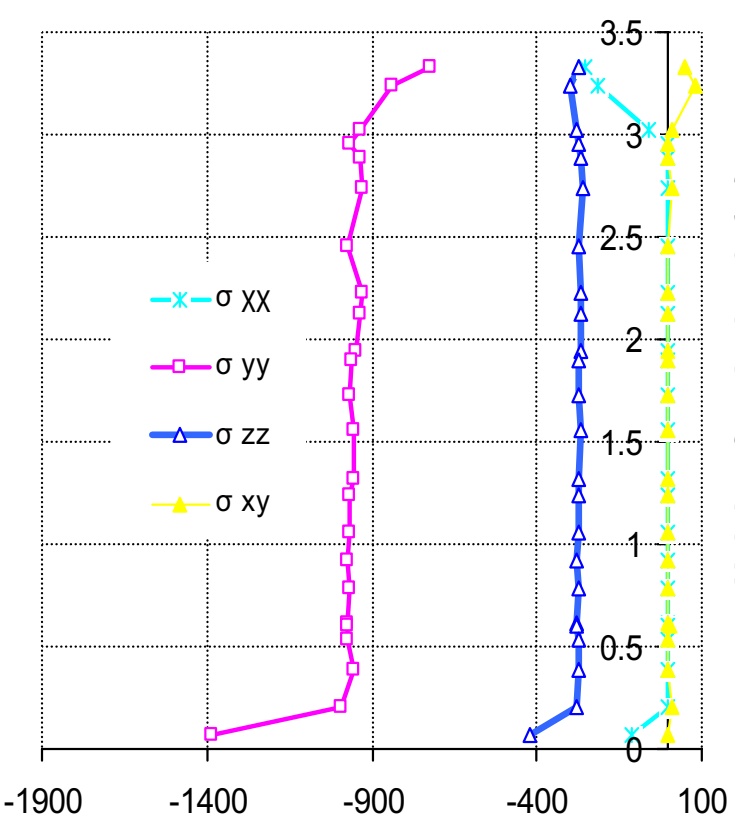

Effective stresses $\left\{\mathbf{k N} / \mathbf{m}^{2}\right\}$

(a)

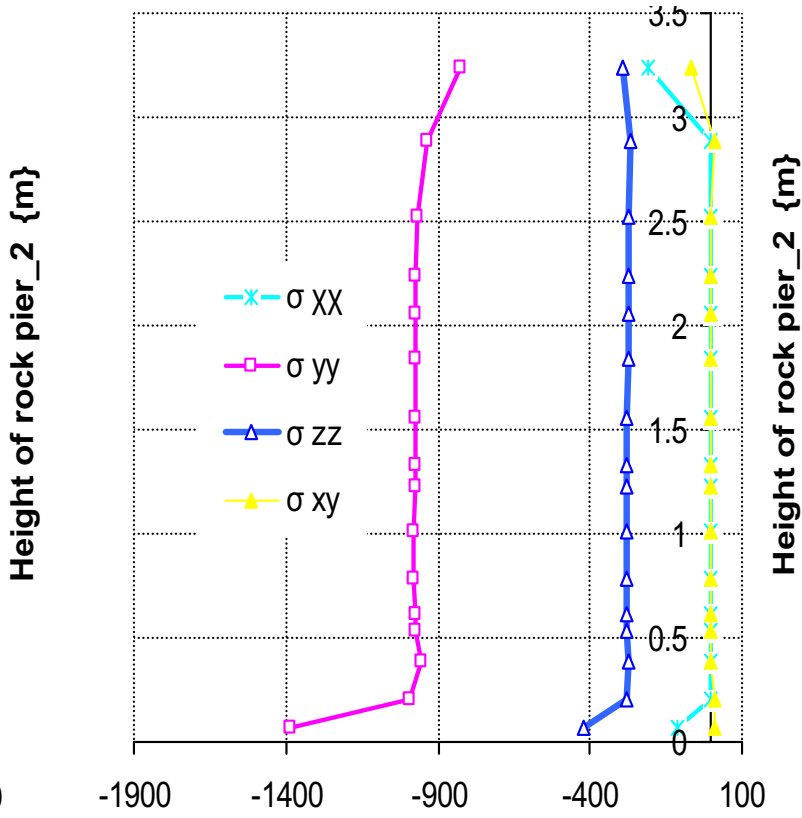

Effective stresses $\left\{\mathbf{k N} / \mathbf{m}^{2}\right\}$

(b)

Fig. 14 Effective compressive stresses distribution through the supporting rock piers_2. a Initial model. b In underground water conditions. Static analysis. The effective compressive stresses on the top of rock piers increased obviously after raising of underground water level 


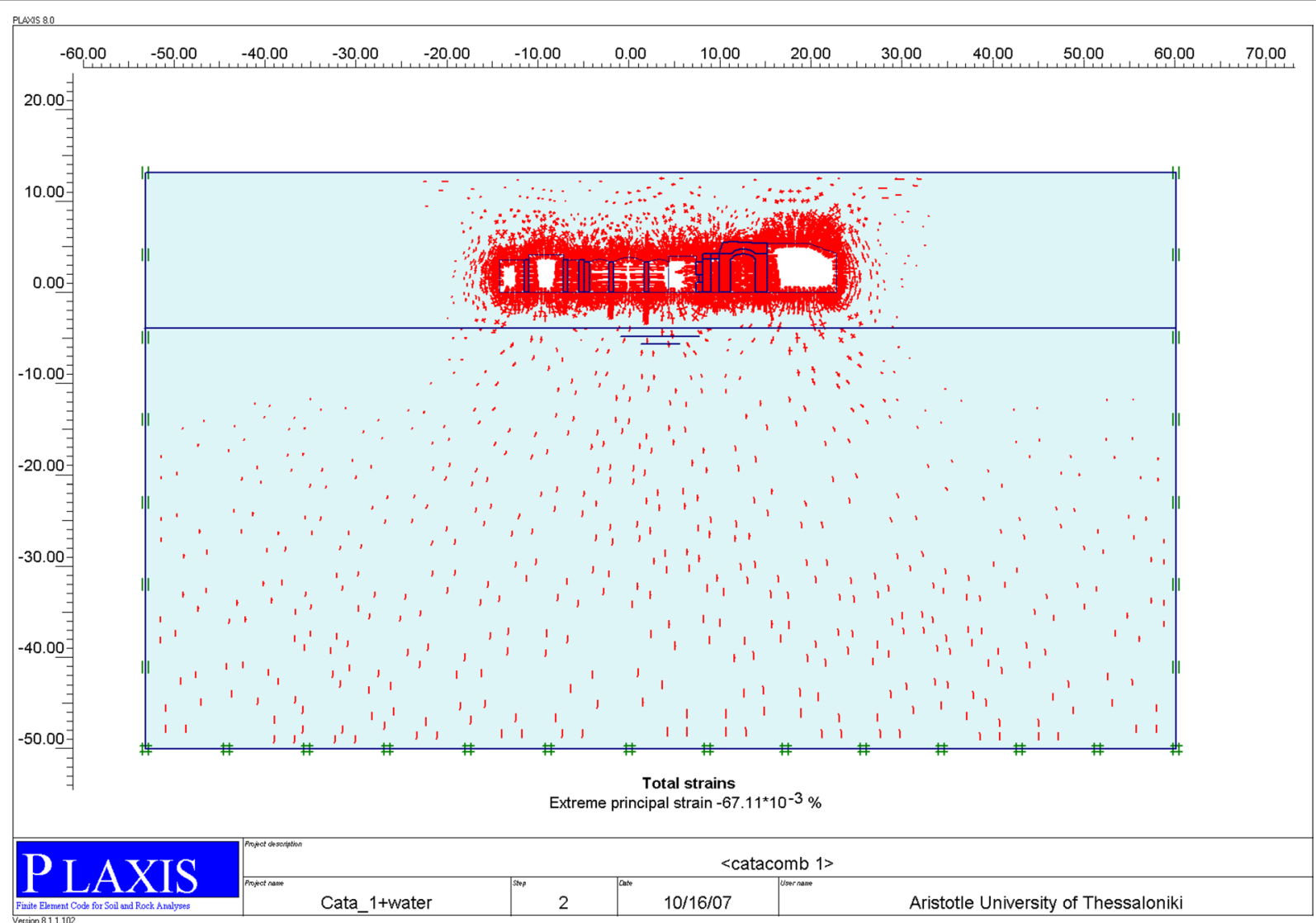

Fig. 15 Total strains. (Peak principal strain $=-67.11^{*} 10^{-3} \%$ ), with underground water, while it was $-66.89 * 10^{-3} \%$. in the initial model. Static analysis

$660.38 * 10^{-6} \mathrm{~m}$ in the underground water conditions, as shown in Fig. 21b.

The peak total compressive stresses in the underground water conditions is $-686.82 \mathrm{kN} / \mathrm{m}^{2}$, while it was $-612.92 \mathrm{kN} / \mathrm{m}^{2}$ in the initial dry model, Fig. 22 represents that the peak total compressive stresses was -612.92 $\mathrm{KN} / \mathrm{m}^{2}$ in the initial dry model, while it is $-686.82 \mathrm{kN} /$ $\mathrm{m}^{2}$ in the underground water conditions.

Also the peak active pore pressure is $-298.49 \mathrm{kN} / \mathrm{m}^{2}$ in the underground water conditions as shown in Fig. 23. The peak principal strain is $-9.98^{*} 10^{-3} \%$ in underground water conditions, while it was $-0.01 * 10^{-3} \%$ in the initial dry model. Figure 24 represents the Evaluation of a global safety factor of the construction processes.

When the phreatic level raised, the bearing capacity of the soil/rock decreases with the rise of the groundwater level, resulting in additional settlement. When the water level rises by $1 \mathrm{~m}$ inside the Catacombs of Kom El-Shoqafa, the cumulative settlement is $2 \mathrm{~mm}$. Therefore, people must pay enough attention to it and take corresponding measures to control the rise of groundwater level and ensure the safety of the archaeological sites in Alexandria.

\section{The mitigation strategies}

Countries with a large number of World Heritage sites at risk should put in place adaptation measures at the national level; The Egyptian government is working to develop a strategy for adaptation to climate change, which will include potential scenarios in the years 2050 and 2100. While the Ministry of Environment and Energy bears full responsibility for the strategy, the Ministry of Culture is involved in drafting cultural heritage impact assessments. The Ministry of Culture says managing climate change risks will be an integral part of the management plan.

Climate change is one of the risks among a number of challenges facing World Heritage sites. This threat must be viewed in the broader context of preserving these sites. 


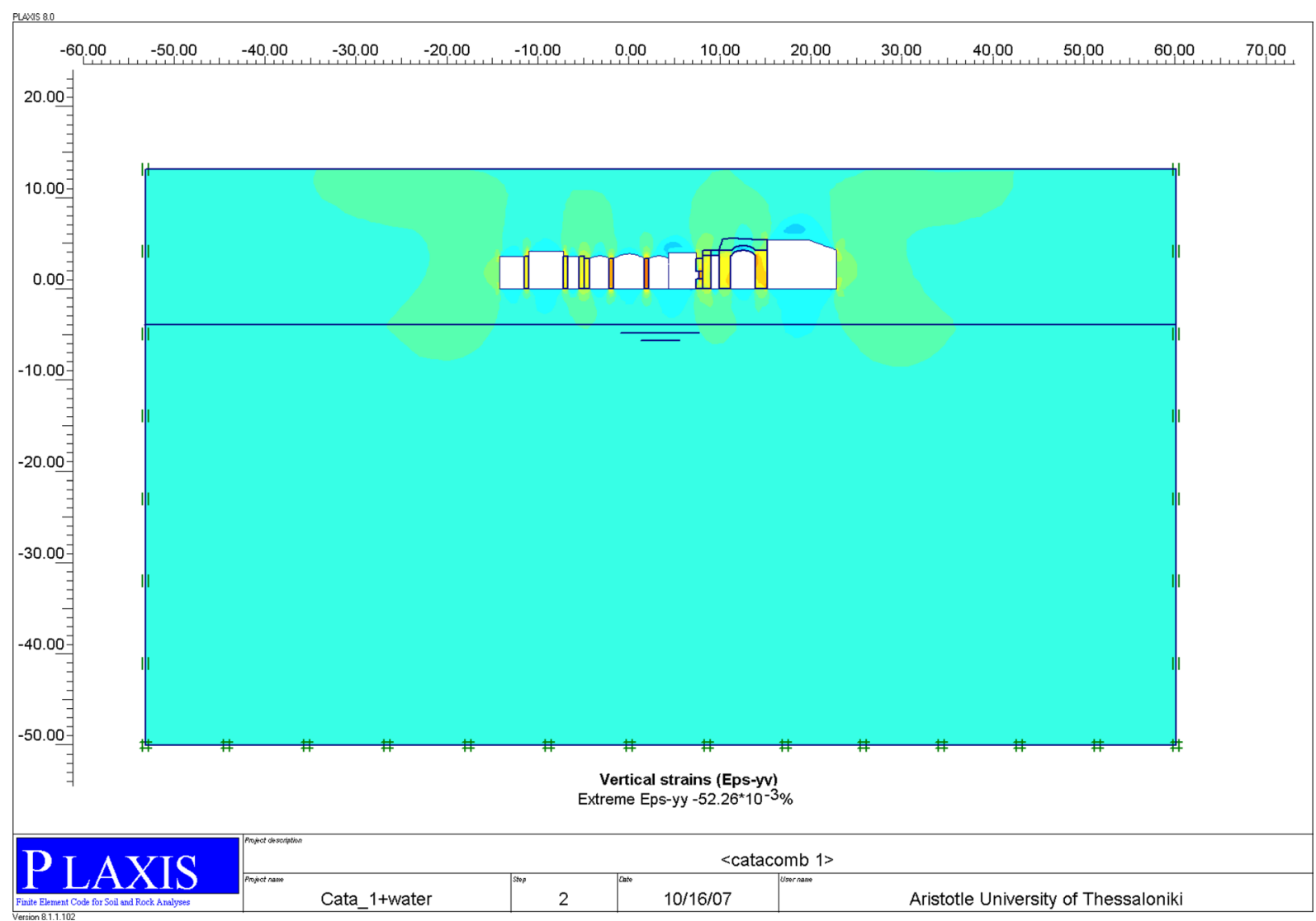

Fig. 16 Vertical strains (Eps-yy). Peak vertical strain, peak Eps-yy $=-52.26^{*} 10^{-3} \%$, and the peak horizontal strain $=-31.99^{*} 10^{-3} \%$, underground water conditions while it was $-31.99^{*} 10^{-3} \%$ in the initial model. Static analysis

The potential impacts of climate change range from physical, social and cultural aspects. In terms of natural heritage, the vast majority of biomes may be negatively affected by the impacts of climate change.

The impacts of climate change affect many and are likely to affect many World Heritage properties, both natural and cultural, in the coming years.

This study represents the first part of forecasting and managing the impacts of climate change on the world heritage of Alexandria.

The mitigation strategy may begin with a review of the nature and magnitude of the risks to World Heritage properties arising in particular from climate change;

Therefore, the main objective of the mitigation strategy is to review the main issues to be taken into account when preparing to implement preventive and/or corrective management responses to deal with the negative impacts of climate change.

Conservation is managing change, and climate change is one of the most important global challenges facing society and the environment today. Actions to be taken to preserve the $3 \mathrm{D}$ heritage:
Preventive measures: monitoring, reporting and mitigating the effects of climate change through environmentally sound choices and decisions at a range of levels: individual, community, institutional and corporate.

Corrective actions: Adaptation to the realities of climate change through global and regional strategies and local management plans.

Knowledge sharing: Including best practices, research, outreach, public and policy support, education and training, capacity building, networks, etc.

It is imperative to implement appropriate management responses to address the threats that climate change poses to their natural and cultural properties inscribed on the World Heritage List.

The Egyptian government, which is struggling to rebuild the economy after the turmoil that followed the Arab Spring in 2011, has allocated more than \$ 120 million for barriers and other protection measures along the beach. Without these barriers, parts of the Corniche and buildings near the shore would be damaged, at an estimated cost of approximately \$ 25 billion, see Fig. 25. 


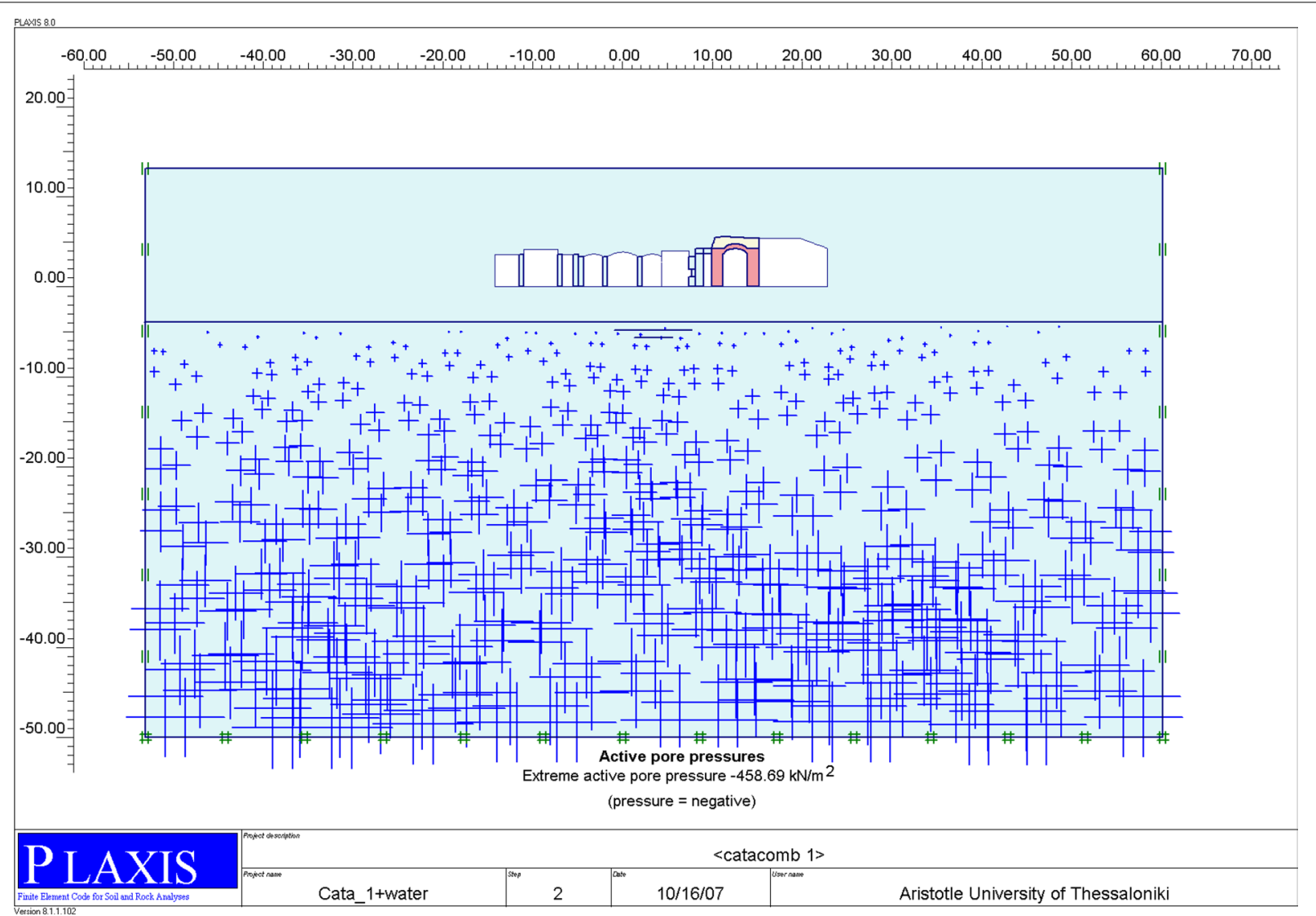

Fig. 17 Extreme active pore pressure $-458.69 \mathrm{kN} / \mathrm{m}^{2}$

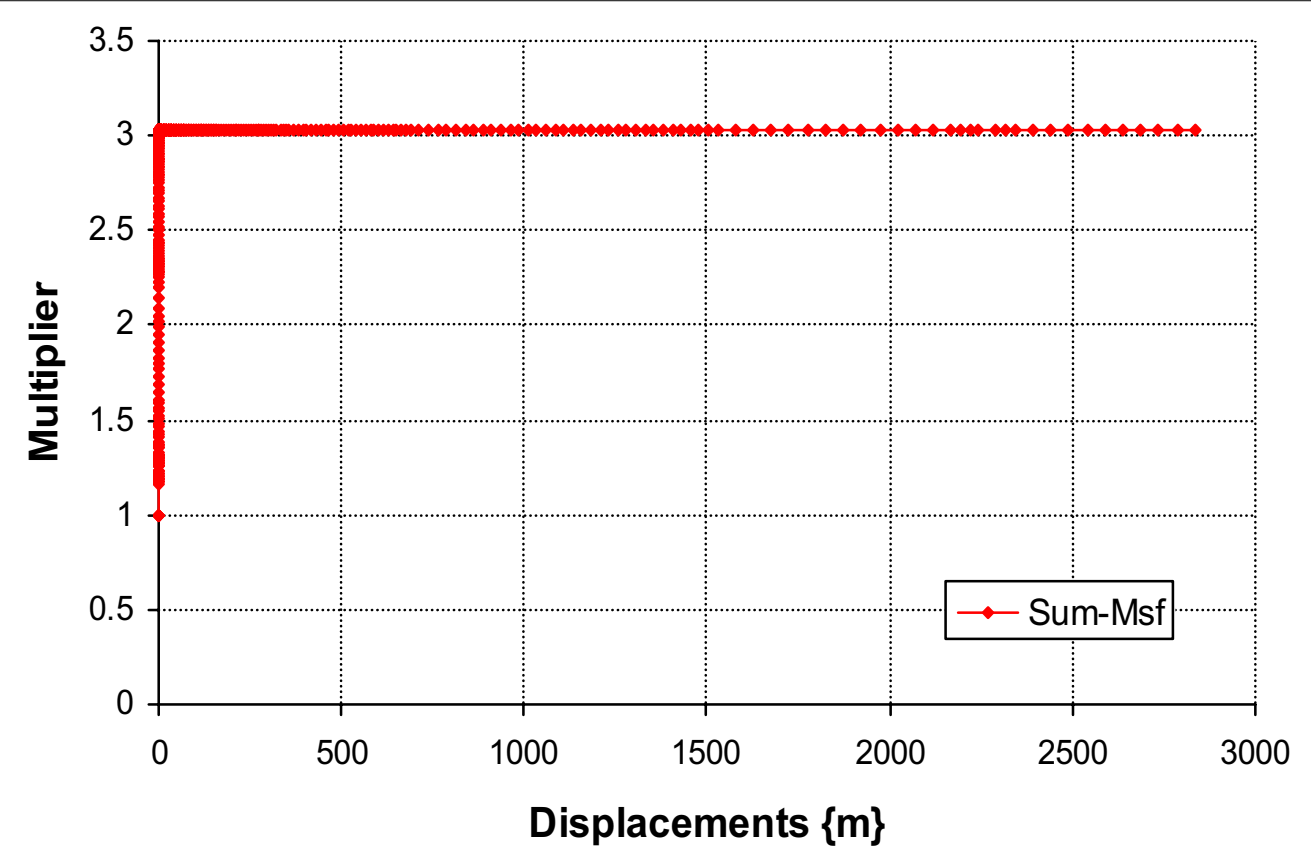

Fig. 18 Evaluation of a global safety factor of the construction processes 

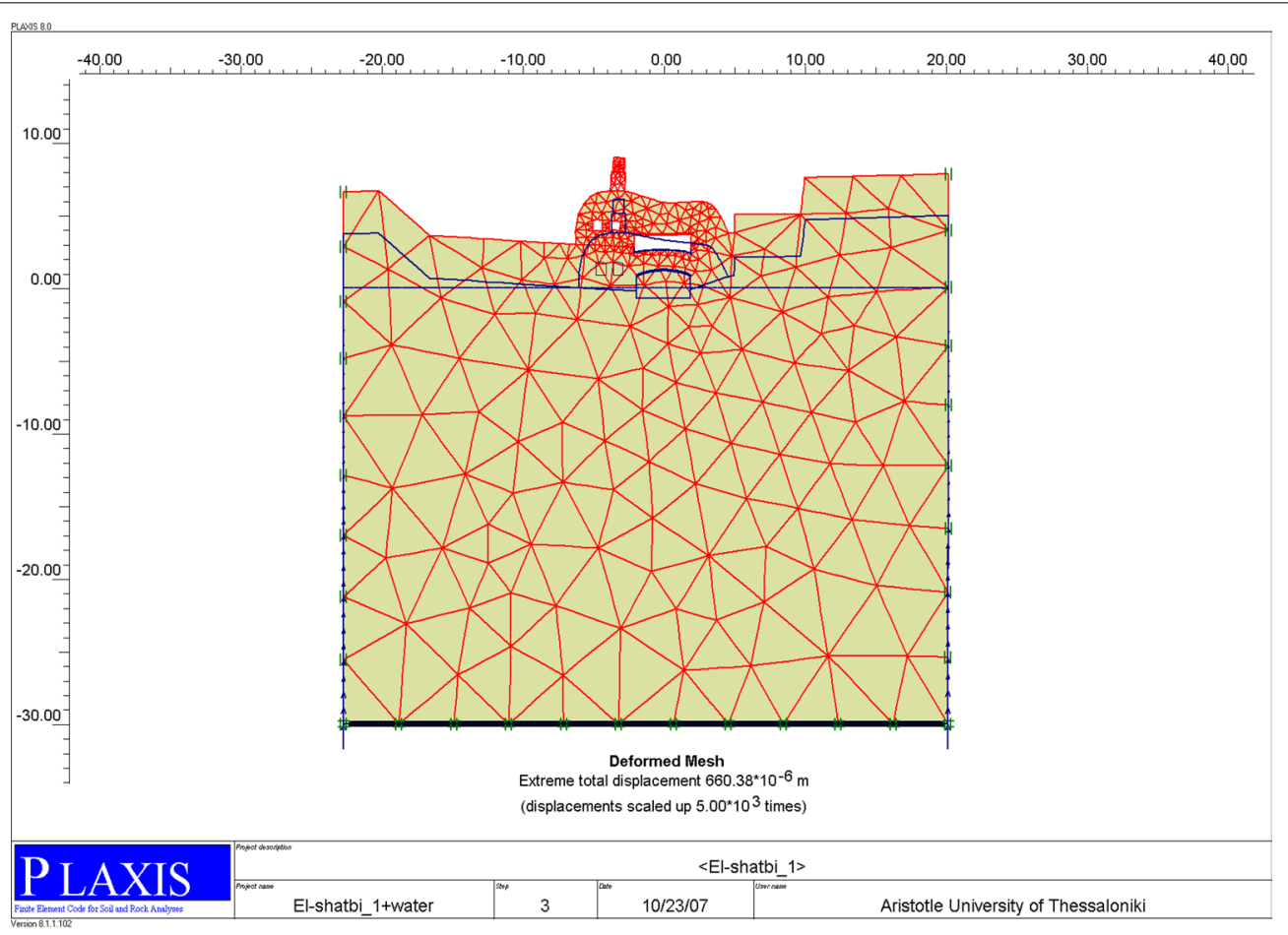

(a)

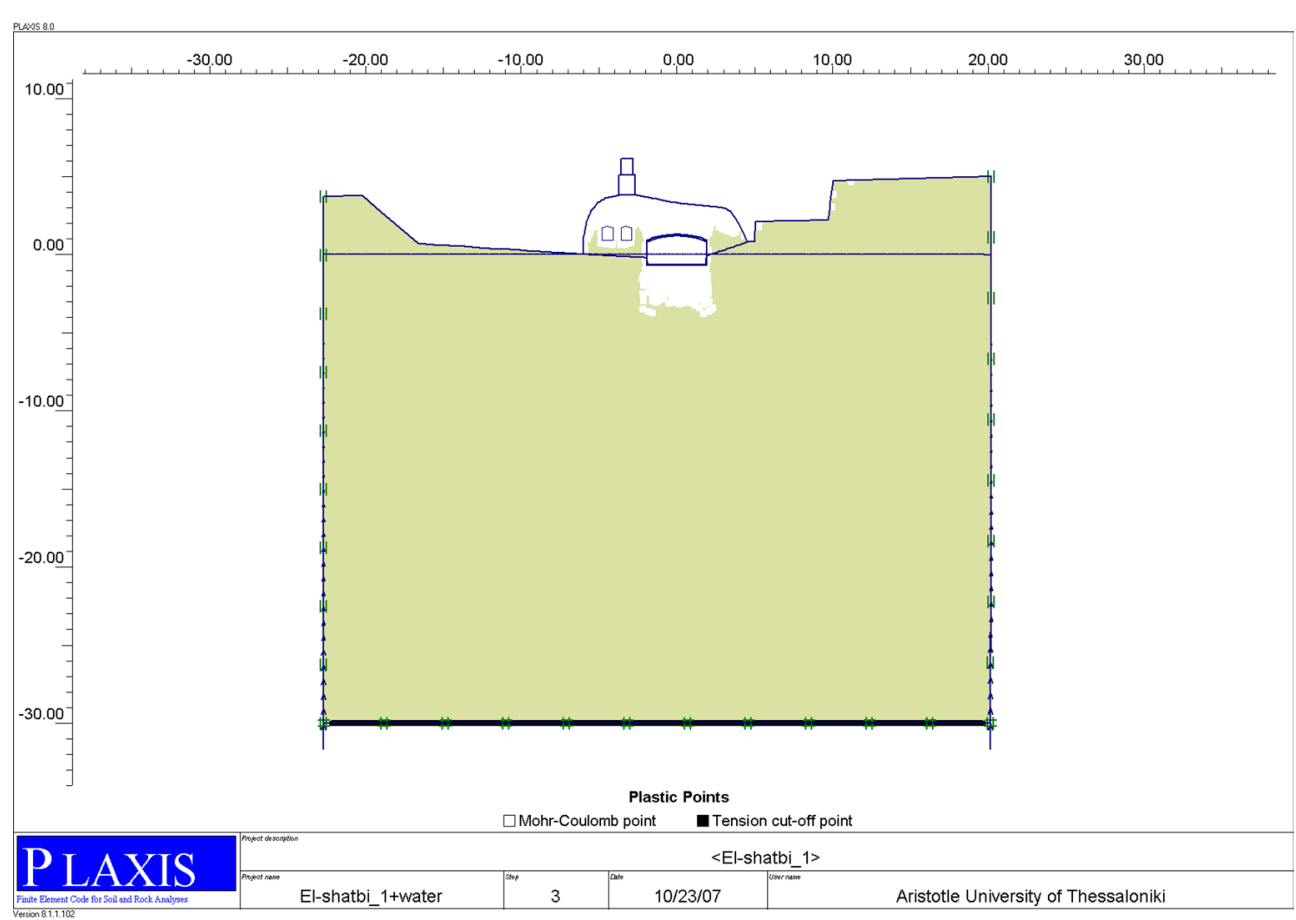

(b)

Fig. 19 a Deformed mesh and boundary conditions. b Plastic points distribution. Static analysis. Underground water conditions 


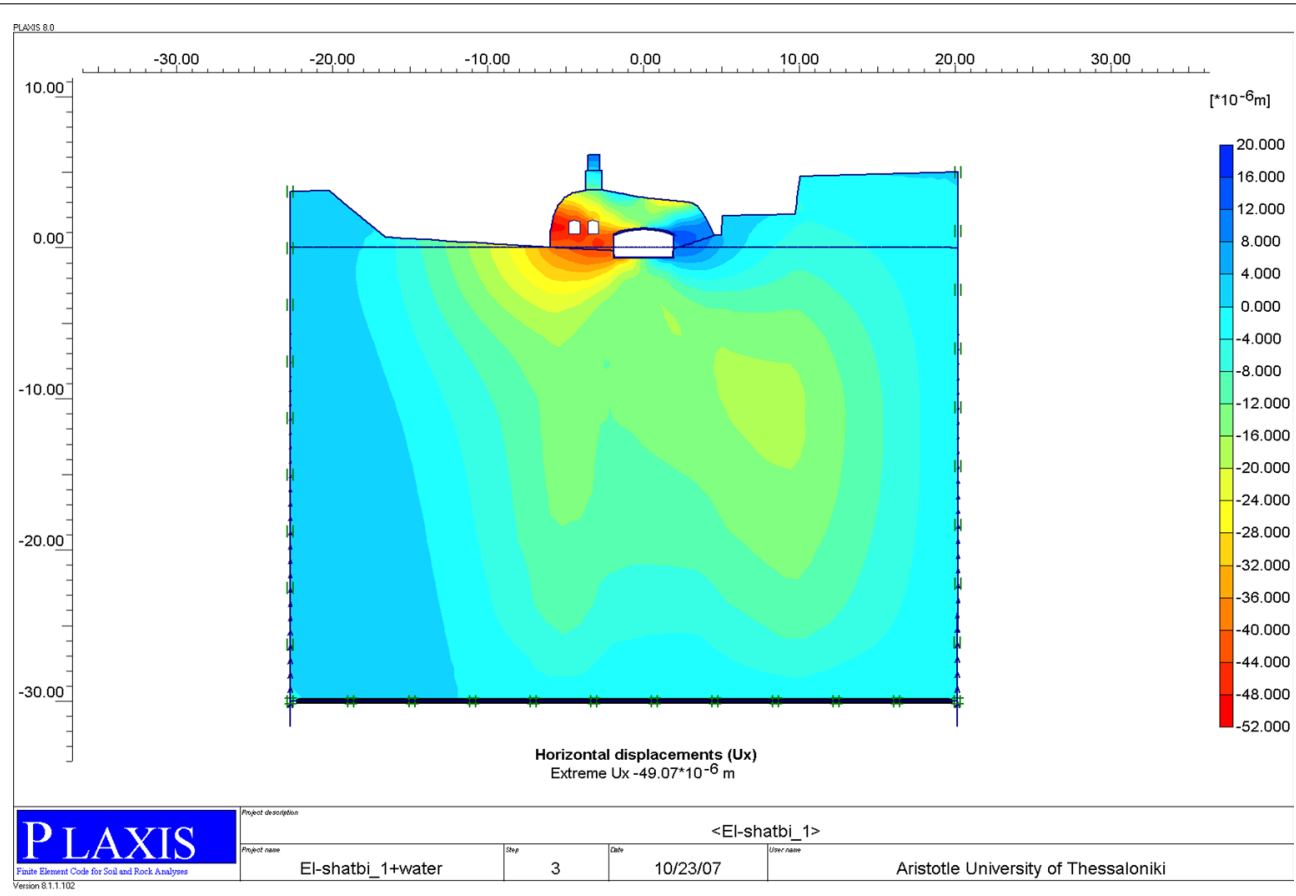

(a)

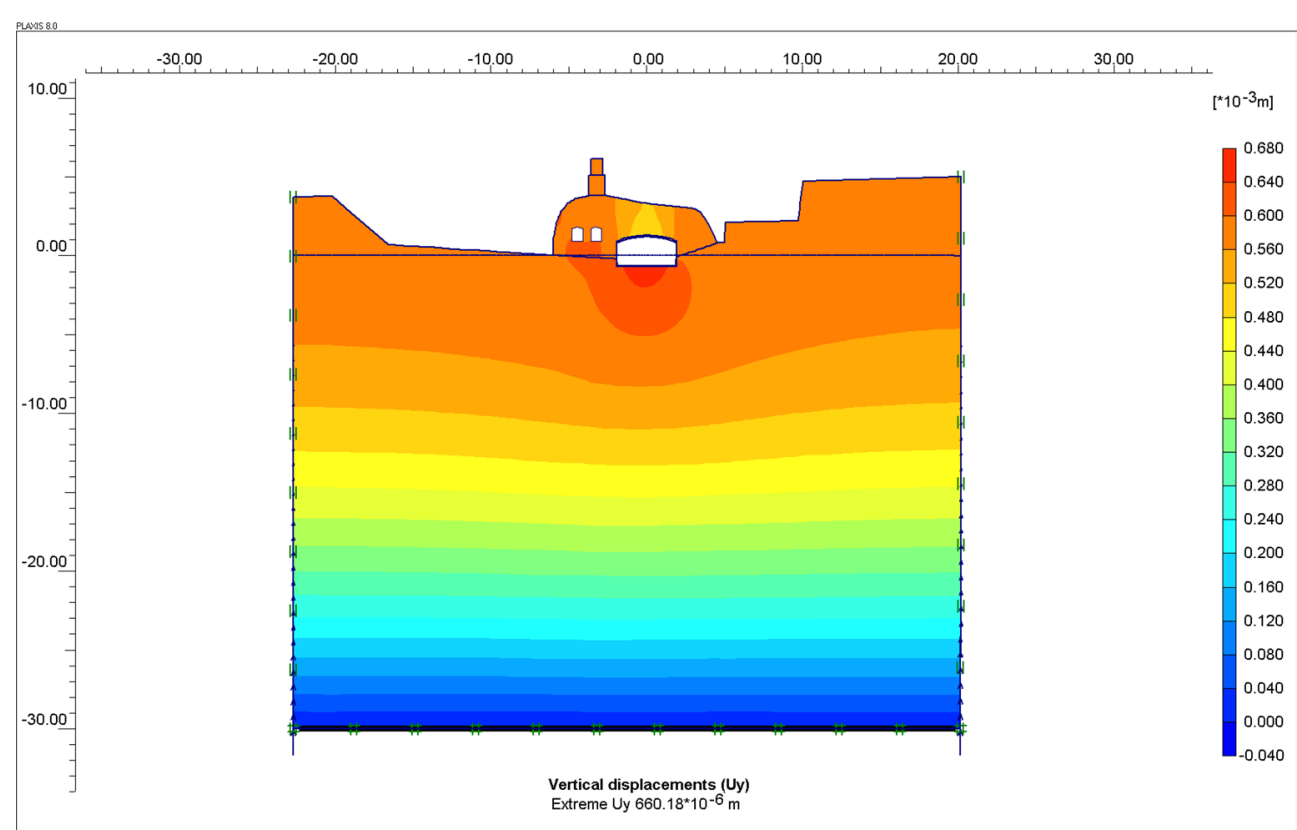

\section{PLAXIS}

\begin{tabular}{|c|c|c|c|}
\hline \multicolumn{4}{|c|}{$<$ El-shatbi_1> } \\
\hline El-shatbi_1+water & 3 & 10/23/07 & Aristotle University of Thessaloniki \\
\hline
\end{tabular}

(b)

Fig. 20 a Peak horizontal displacements $U x=-49.07 * 10^{-6} \mathrm{~m}$. b Peak vertical displacements $U y=660.18^{*} 10^{-6} \mathrm{~m}$ inside the excavations. Static analysis. Underground water conditions 


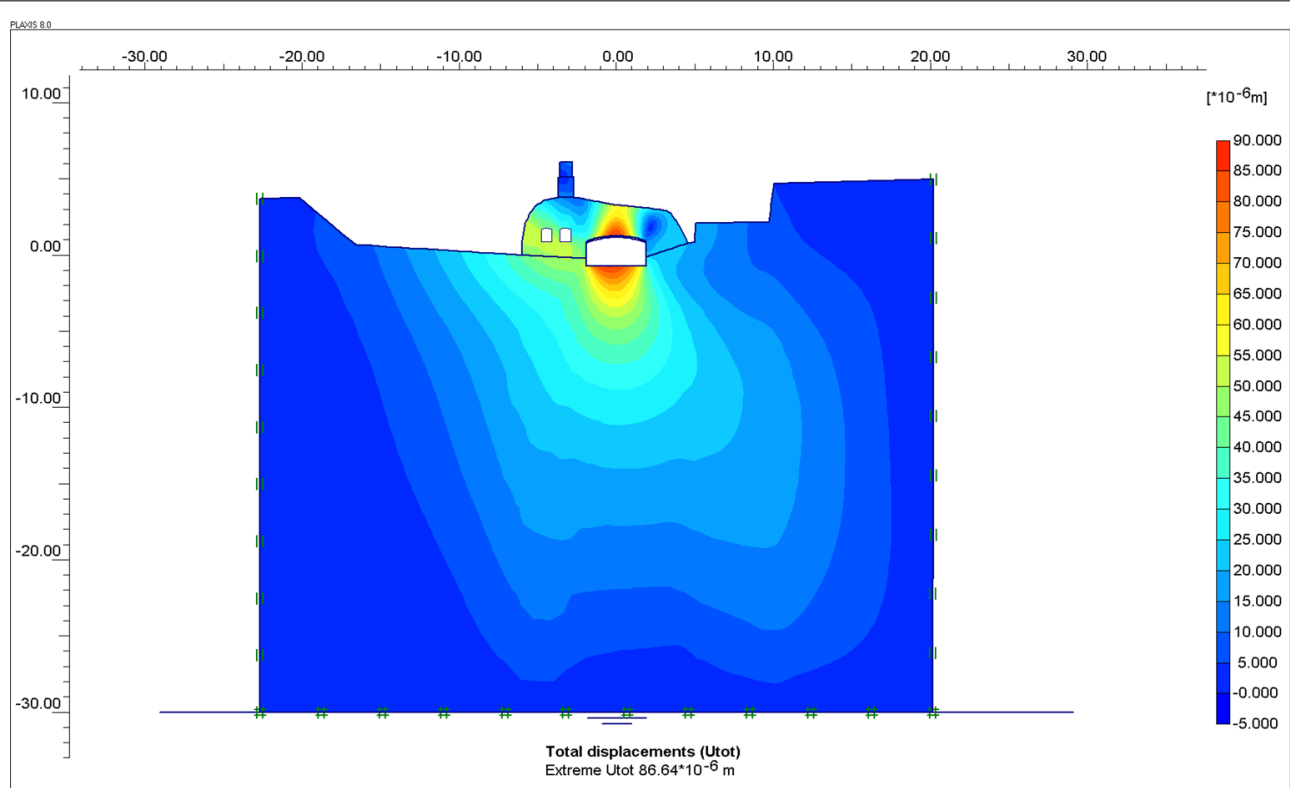

\section{P LAXIS}

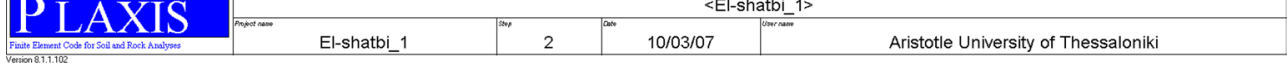

(a)

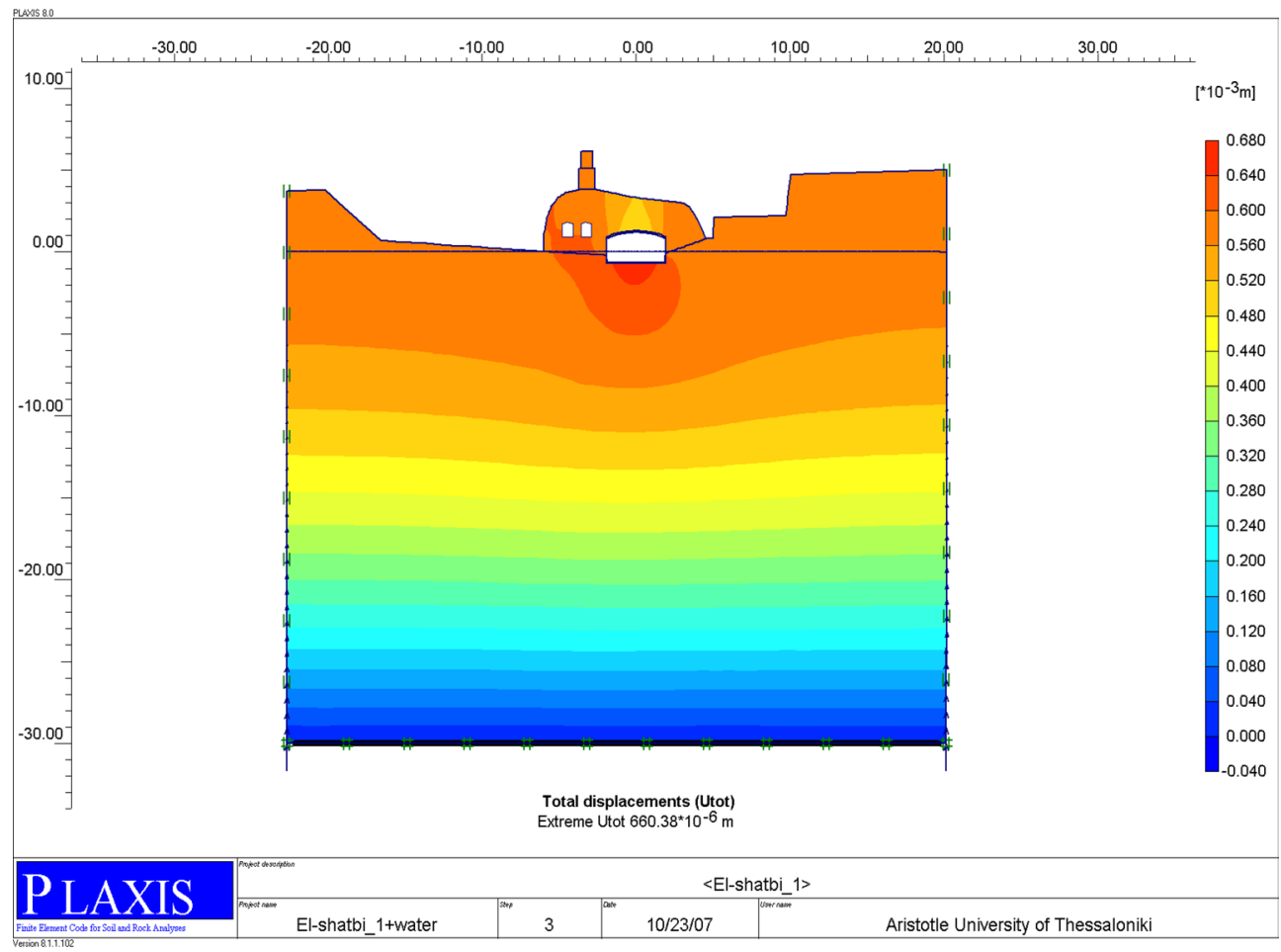

(b)

Fig. 21 a Peak Total displacement $=86.64 * 10^{-6} \mathrm{~m}$ in the initial model, $\mathbf{b}$ while it is $660.38 * 10^{-6} \mathrm{~m}$ in underground water conditions 


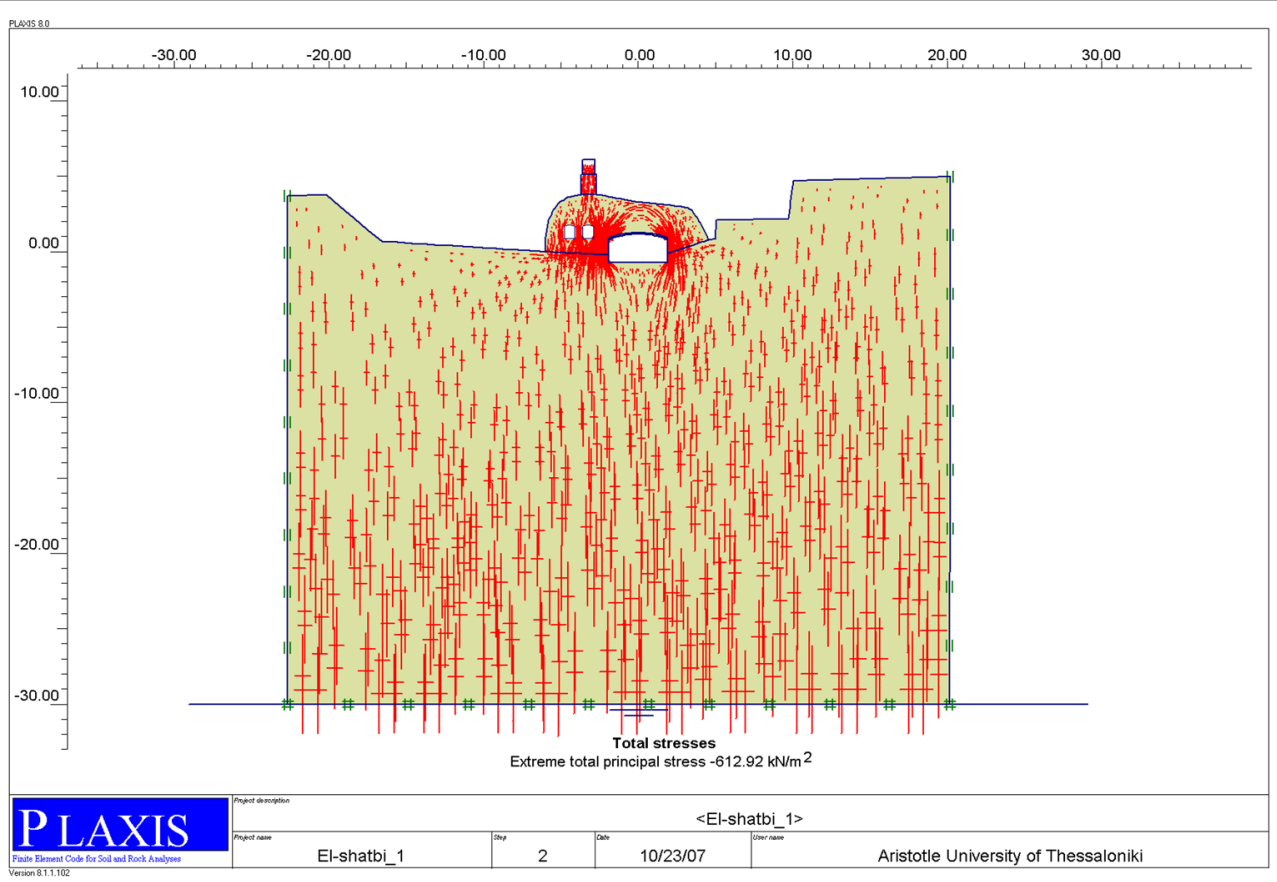

(a)

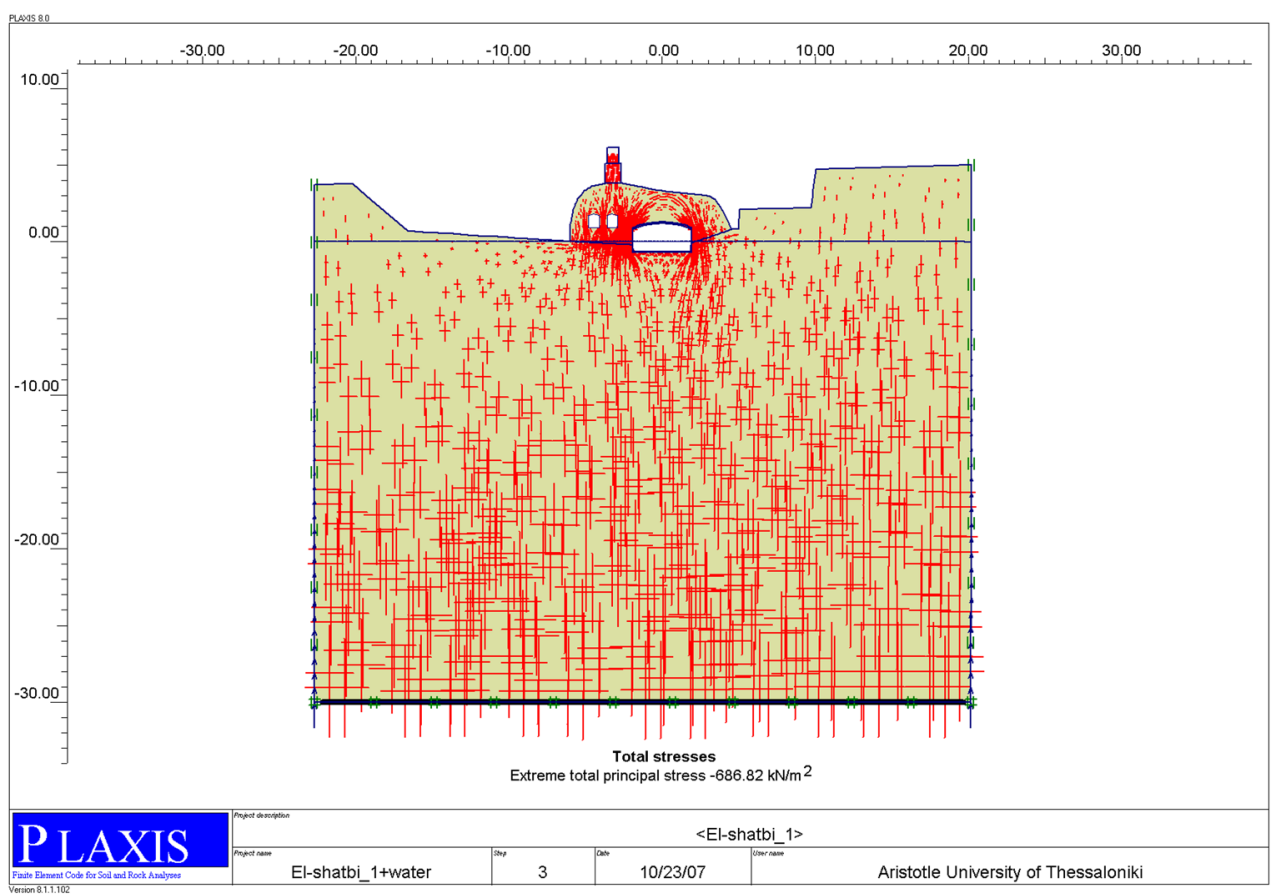

(b)

Fig. 22 a Peak total compressive stresses $=-612.92 \mathrm{KN} / \mathrm{m}^{2}$ in the initial model, $\mathbf{b}$ while it is $-686.82 \mathrm{KN} / \mathrm{m}^{2}$ in the underground water conditions. Static analysis 


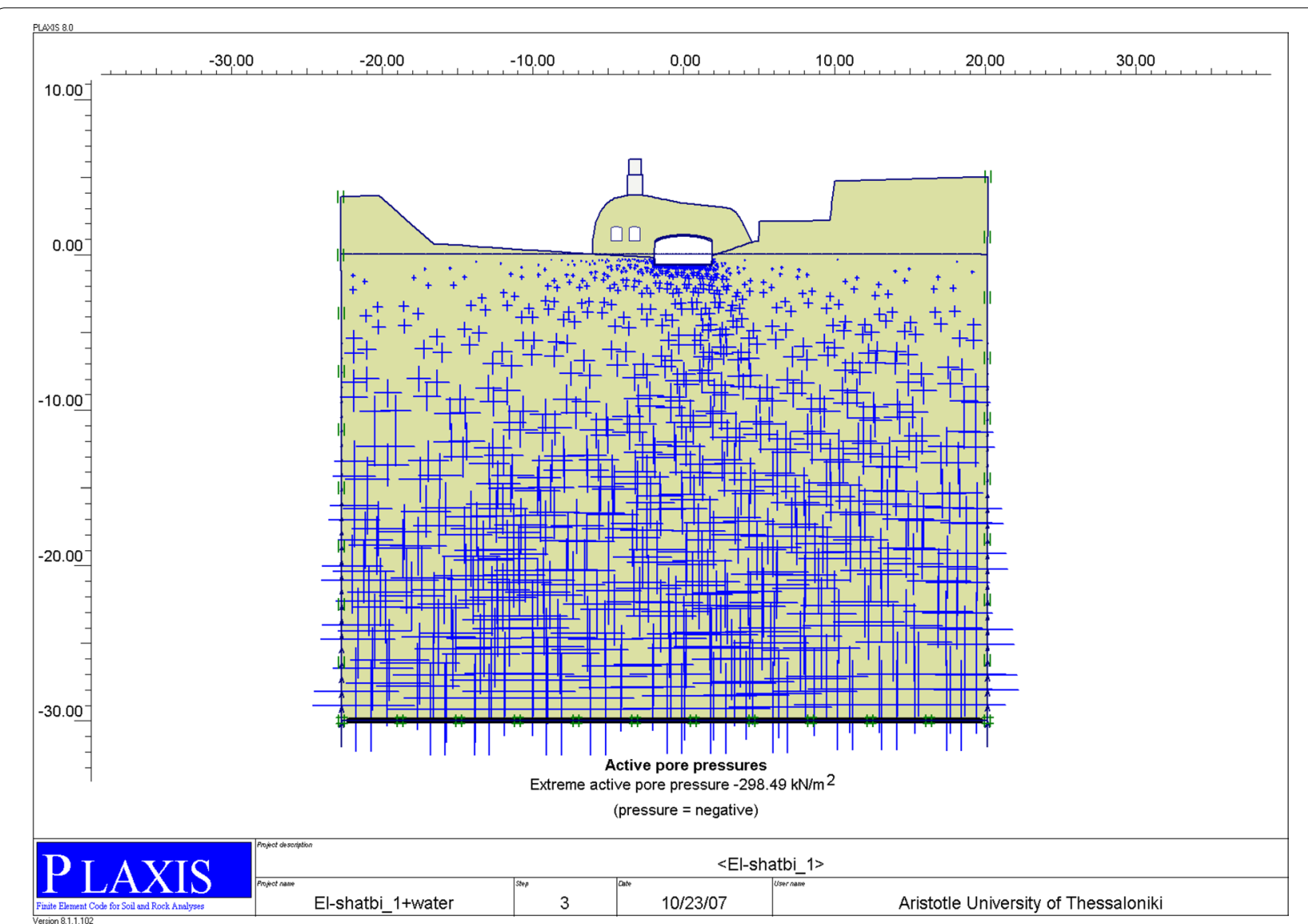

Fig. 23 Peak active pore pressure $=-298.49 \mathrm{kN} / \mathrm{m}^{2}$

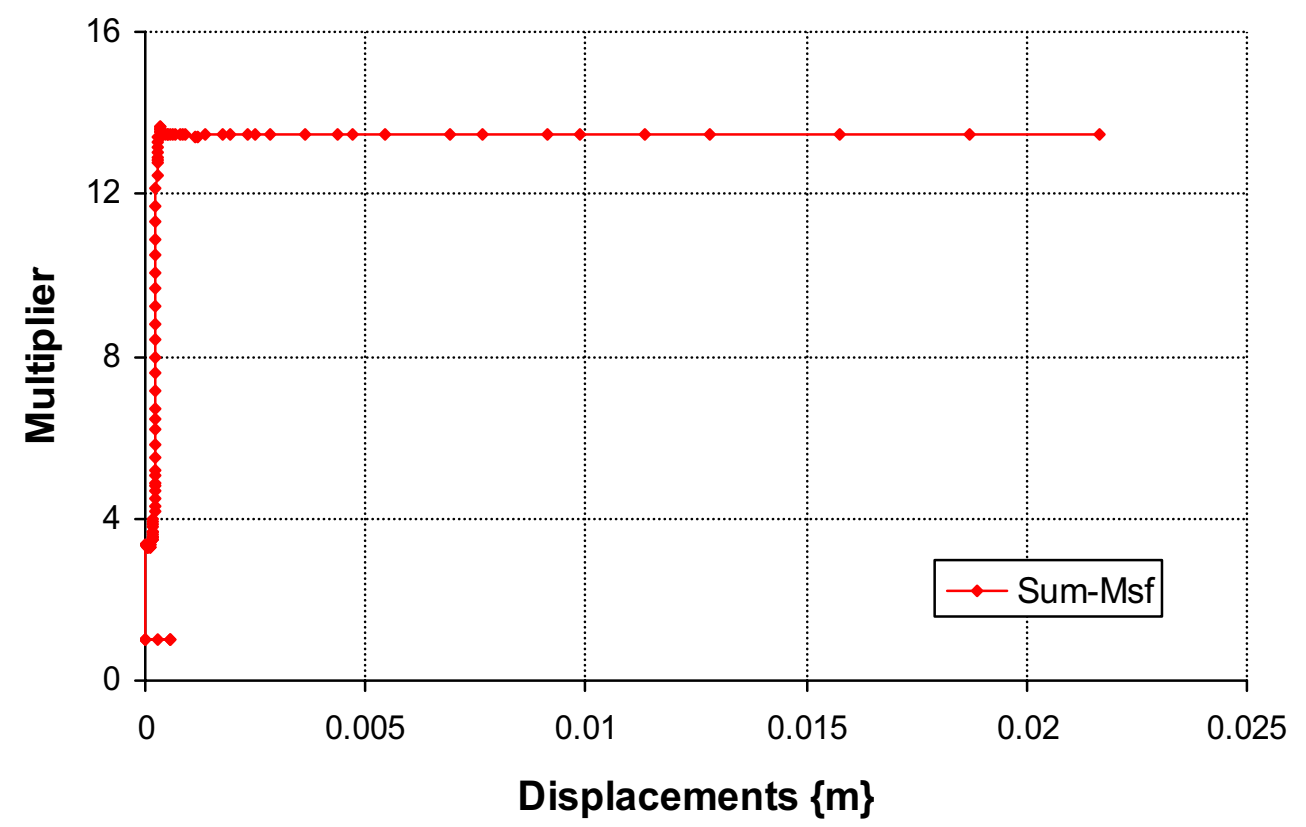

Fig. 24 Evaluation of a global safety factor of the construction processes 

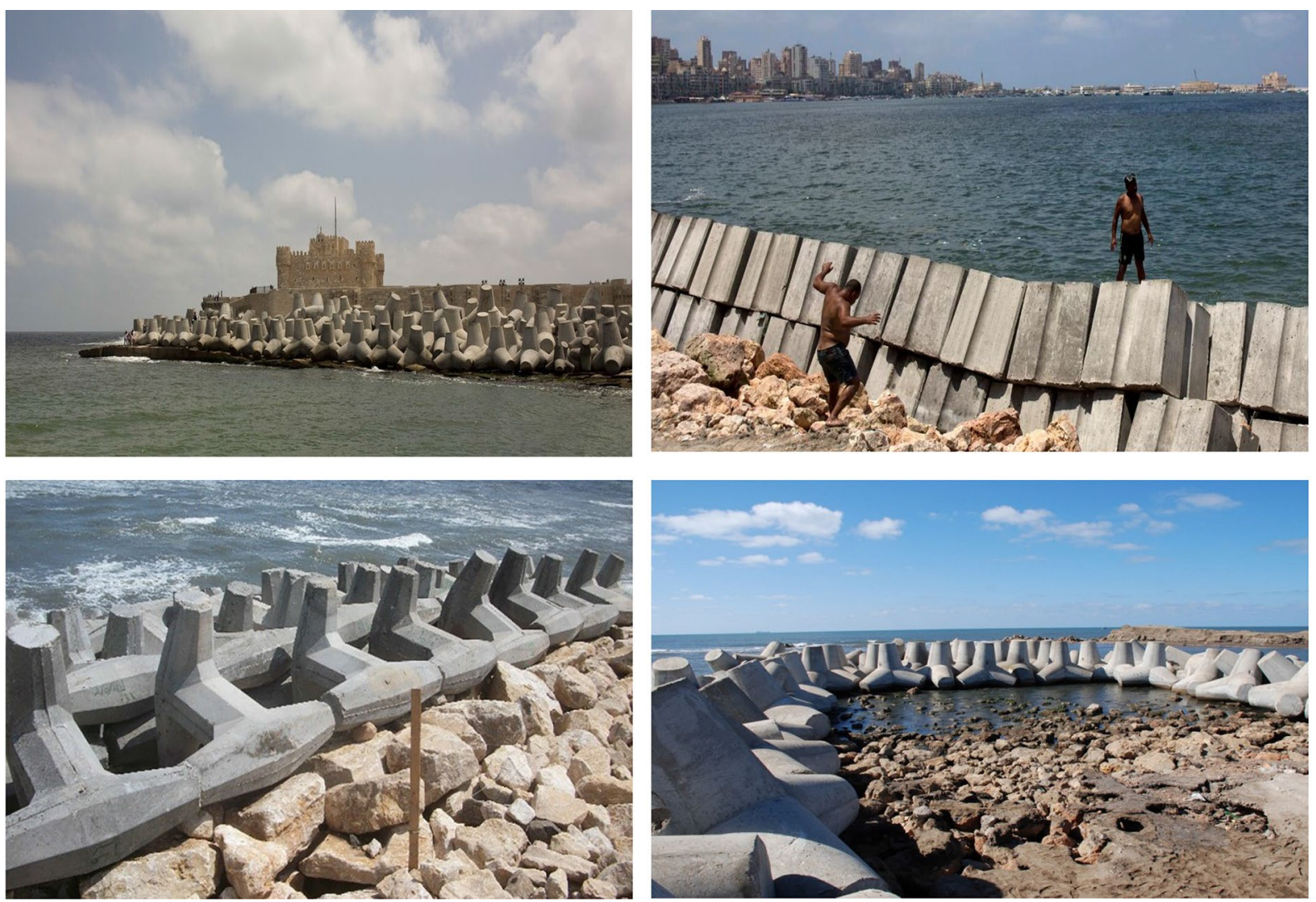

Fig. 25 A cement barrier placed as reinforcement against rising water levels near the citadel. b. The barriers and other protective measures along the shore of Alexandria. In this August 8, 2019, photo, workers prepare to place cement blocks to reinforce the sea wall against rising water levels on the corniche in Alexandria, Egypt

As a result of the bad environmental situation around the archaeological area of Kom al-Shuqafa, it became necessary to choose some suitable places to dig some trenches to collect groundwater from the study area in Kom al-Shuqafa. In fact, because the groundwater level has become a great danger to the temples area after the construction of the new arches of Kom al-Shuqafa, it is necessary to work on drainage networks covered with a layer of sponge to draw underground water or dig trenches at certain distances from the temple to withdraw the wastewater slowly to avoid cracking the walls of the temple. The methodology includes a GIS technology phase to identify the possible possible sites based on external influence factors such as roads, DEM, archaeological area, cultivation.

\section{Kom El-Shoqafa groundwater lowering project}

The Kom el-Shuqafa Groundwater Lowering Projectwhich began on October 12, 2017 and was completed on 13 March 2019-aimed to address these issues by reducing the threat of water infiltration. Between the December 2, 2017 and September 27, 2018 field archaeologists were present on site to monitor and record any archaeological remains at risk of impact (removal) by the project construction activities, primarily below ground cutting works.

The Kom el-Shoqafa groundwater lowering system was designed to collect and convey about 600 to 700 $\mathrm{m} 3 / \mathrm{hr}$ of groundwater. Collection entails six pumped deep wells, designed to draw down the groundwater to a target elevation of $-4.2 \mathrm{~m} \mathrm{BSL}, 2$ to $3 \mathrm{~m}$ below the lowest level in the catacombs.

The wells will pump groundwater through force mains connected to a gravity line constructed of HDPE from where it was originally planned to discharge the water into the Mahmoudia Canal, prior to implementation of the Alexandria Governorate's Mahmoudia Canal Development Project which would see the canal backfilled. The canal was an obvious place for the discharge in the design stage and at project inception and it was the first choice, but a new discharge had to be found due to reasons outside CDM Smith's control when the municipality decided to backfill the canal. The engineering design 


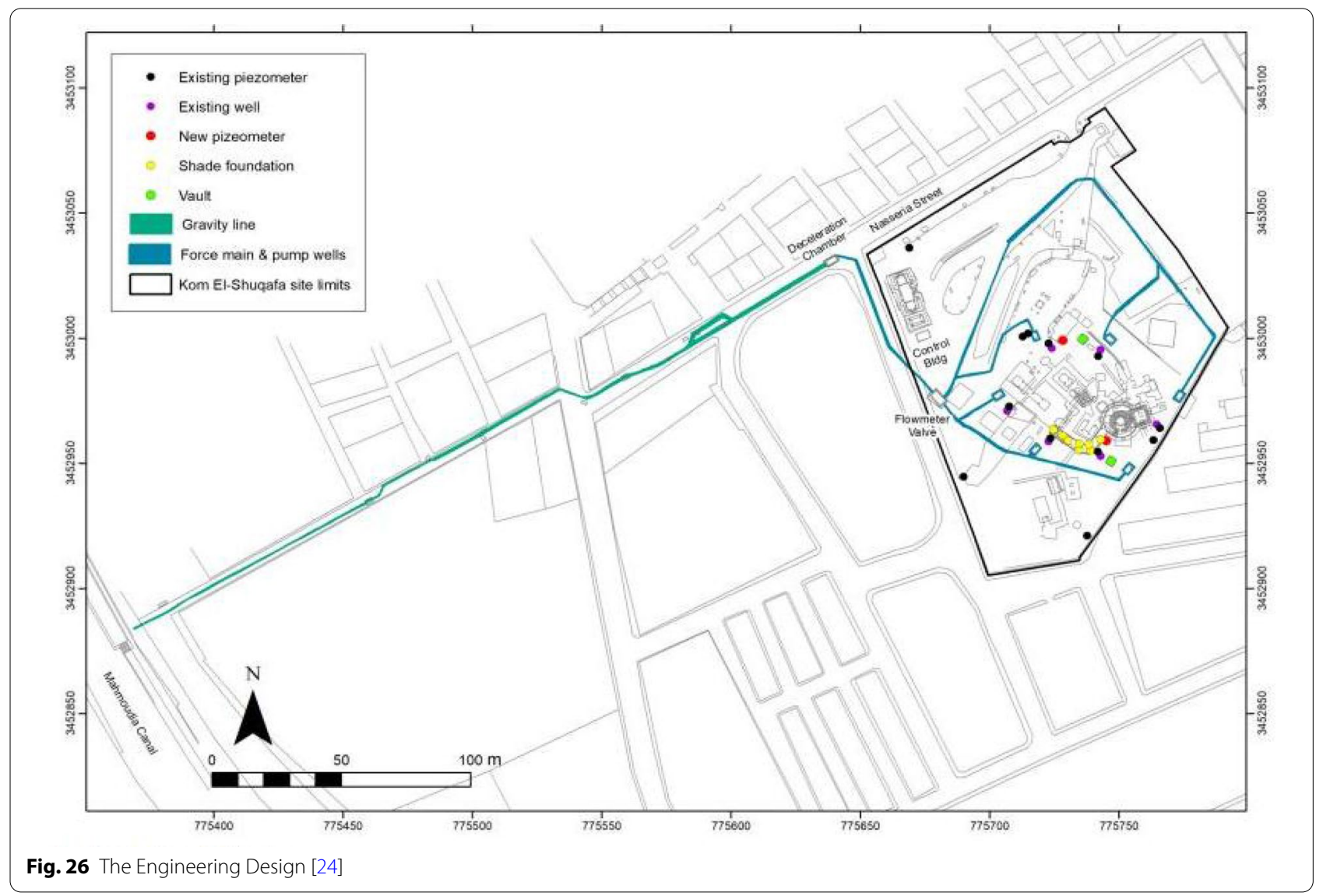

Figs. 26, 27, and 28 included the following system components:

\section{- Construction of Deep Wells}

The vertical deep wells consist of six pumping wells $43 \mathrm{~m}$ deep with an inner diameter of approximately $305 \mathrm{~mm}$ including the connecting piping, and well vaults.

- Construction of groundwater force main and gravity pipelines

The groundwater force main is approximately 450 linear meters of HDPE pipe with pipe sizes ranging from 150 to $350 \mathrm{~mm}$ including the flow meter/valve vault. The groundwater gravity pipeline is approximately 320 linear meters with a diameter of $350 \mathrm{~mm}$ HDPE pipe including the deceleration chamber.

- Construction of piezometers

This includes two new piezometers and modifying the six existing wells for use as permanent piezometers complete with new manholes. In addition, the twelve existing piezometers will be modified to be permanent piezometers. The modification of the six existing wells will not commence until after the start-up of facilities. The modification of the six existing wells includes complete demolition of the existing system and restoration of the old well vaults to match surrounding pavements and grades. The existing vaults and manholes have holes in the bottom for drainage and the entire structure is filled with sand. The first linear meter of every pipe segment between vaults and manholes is sealed by grouting, including the existing outfall pipe at El Mahmoudia Canal.

Pavements and grades have been restored in this area. The two new piezometers have been installed, complete with pipes, well screens, filter packs, and below ground vaults including water level indicator transmitters, combined power, control switchboards, and connections to a SCADA system.

- Construction of an outfall

As noted above, once the Mahmoudia Canal is filled as part of the Mahmoudia Canal Development Project, the gravity line will be connected to a manhole of the newly constructed pipeline. This design replaces the cascading outfall which would have discharged the groundwater into the canal.

- Construction of a control building 


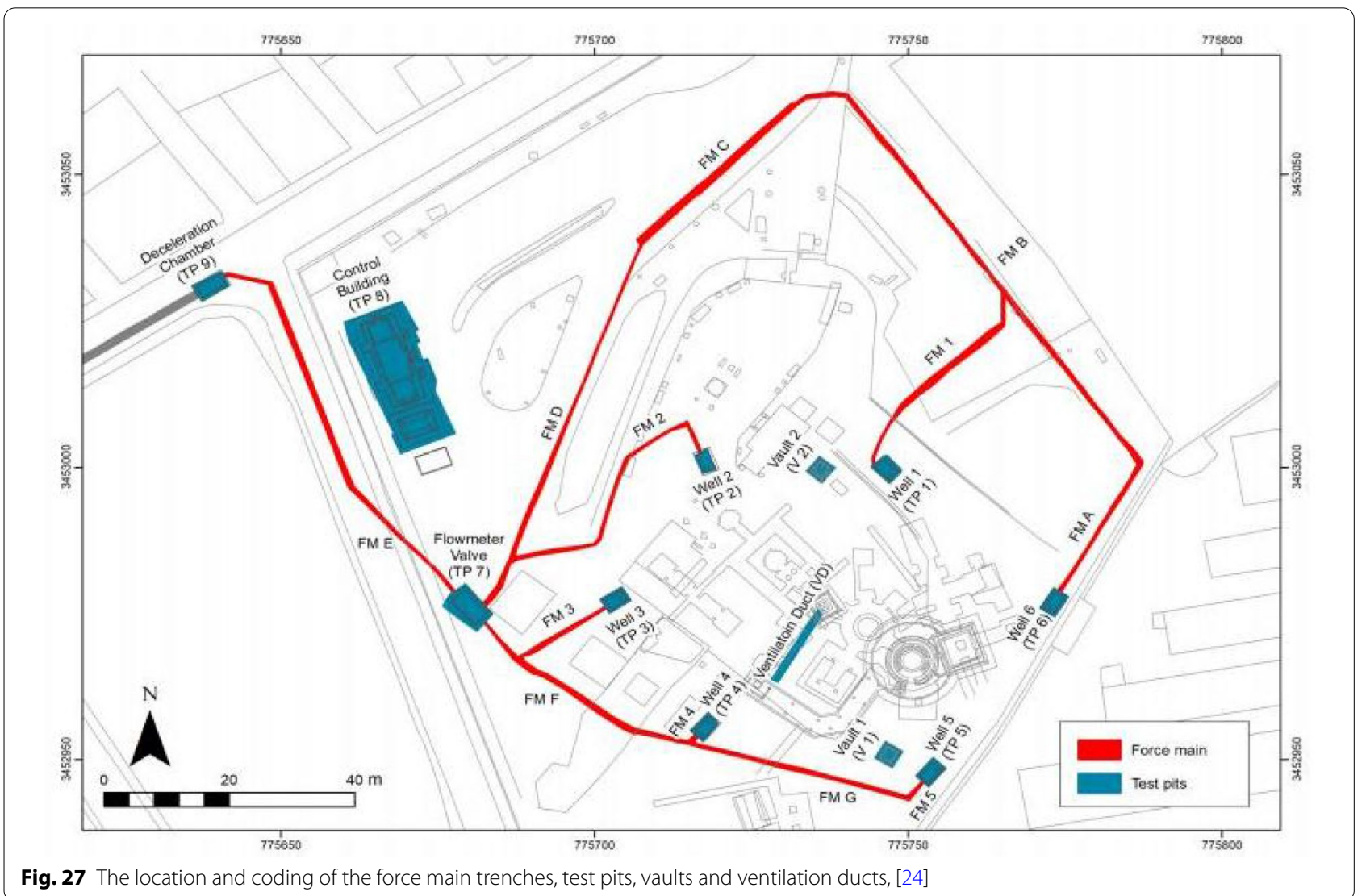

A complete building will be constructed to house all the mechanical, control and electrical equipment including the SCADA system. This will be accompanied by the reinstatement of the surrounding area.

- Construction of an access road connecting the existing road to the control building together with a parking area.

- Construction of shelters; the 'Caracalla shaft' cover and ventilation fan room. A steel structure for a shelter-including a fan room situated within the shaded seating structure and connecting to a stainless-steel duct placed inside the existing ventilation shaft-has been constructed.

- One year of training and operation and maintenance.

The project also entails training the MoA assigned staff; start-up; and operation and maintenance of the complete system for one year. Figure 29 represents the northwest and northeast facing sections of TP5 showing the truncation of the limestone bedrock [24].

\section{Conclusion}

Floods cannot always be prevented and this definitely applies to the Alexandria flood in October 2015 should be more prepared for floods as this type of event is likely to occur more frequently due to climate change. The observed consecutive individual storm events are events of low likelihood and the persistence and clustering of these large rainstorm events was exceptional. The October 2015 storm led to floods in Alexandria of historic proportions, such as the Kom al-Shaqfa cemeteries and the Shatibi necropolis. The risk of these rainwater cluster events cannot be properly managed using conventional methods as they are not designed to bypass or fail.

One of the first short-term and inexpensive mitigation measures could be using precipitation forecasting in modeling rainwater. 


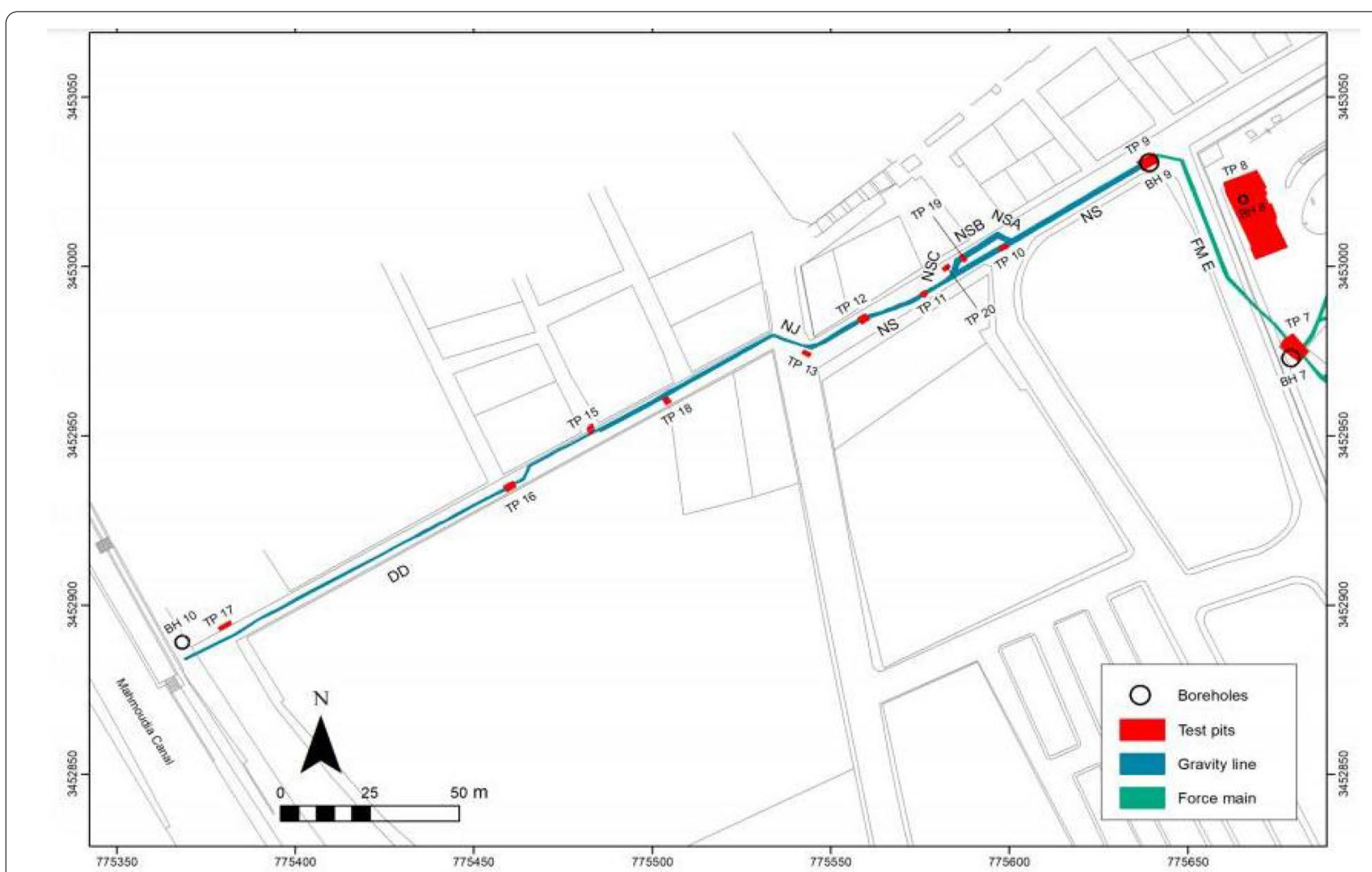

Fig. 28 The location and coding of the force main trenches, test pits, vaults and ventilation ducts, [24]

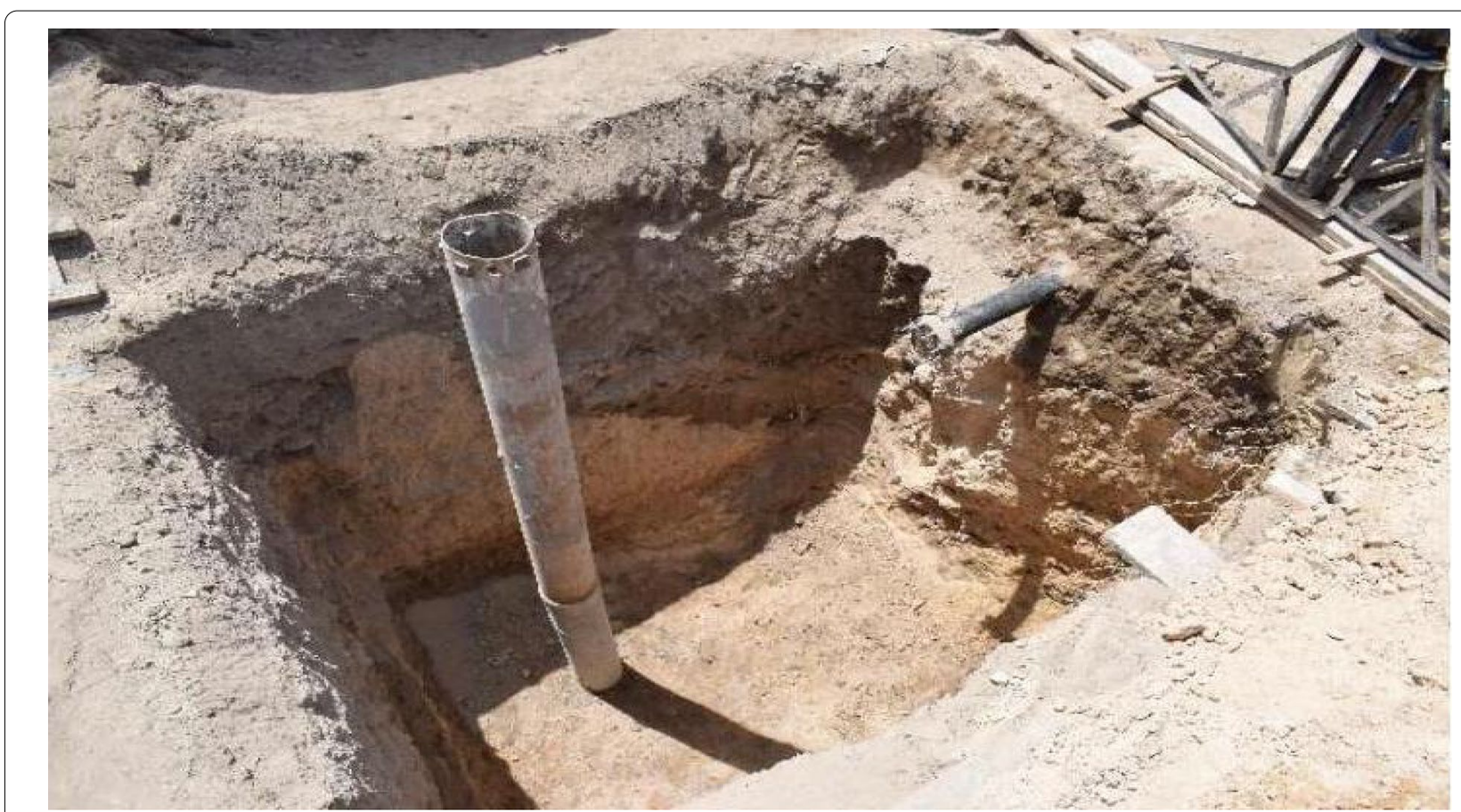

Fig. 29 The northwest and northeast facing sections of TP5 showing the truncation of the limestone bedrock 


\section{Acknowledgements \\ Not applicable.}

\section{Authors' contributions}

The whole database construction and analysis are presented in the manuscript had been achieved by the author. The author read and approved the submitted manuscript.

\section{Funding}

The author confirms that he is not currently in receipt of any research funding relating to the research presented in this manuscript.

\section{Availability of data and materials}

Not applicable. Data sharing not applicable to this article as no datasets were generated or analyzed during the current study.

\section{Declarations}

\section{Competing interests}

The author declare that he has no competing interests.

\section{Author details}

${ }^{1}$ Conservation Department, Faculty of Archaeology, Cairo University, Giza, Egypt. ${ }^{2}$ Institute of Basic and Applied Science - (BAS), Egypt-Japan University of Science and Technology (E-JUST), New Borg El-Arab city, Alexandria 21934 Egypt.

Received: 20 April 2021 Accepted: 6 June 2021

Published online: 17 June 2021

\section{References}

1. UNISDR-CRED Economic losses, poverty \& disasters: 1998-2017 United Nations Office for Disaster Risk Reduction (UNISDR), Centre for Research on the Epidemiology of Disasters (CRED), Geneva, Switzerland and Brussels, Belgium; 2018. Available athttps://www.unisdr.org/files/61119_crede conomiclosses.pdf.

2. Martínez-Austria P, Jano-Pérez JA. Climate change and extreme temperature trends in the Baja California Peninsula, Mexico. Air Soil Water Res. 2021;14:1-11.

3. Lizhu M, Zhonghua Z, Yue T. The Influence of Groundwater Level Rise on Bearing Capacity of Sand Foundation. IOP Conf Ser Earth Environ Sci. 2019:304:022089. https://doi.org/10.1088/1755-1315/304/2/022089.

4. Xie L. Experimental study on the influence of water level rise and fall on bearing capacity and settlement of coarse sand foundation. J Eng Geol. 2013;21:871-7.

5. https://www.bentley.com/en/products/product-line/geotechnical-engin eering-software/plaxis-2d.

6. Hemeda S. 3D finite element coupled analysis model for geotechnical and complex structural problems of historic masonry structures: conservation of Abu Serga church Cairo Egypt. Herit Sci. 2019;7:6.

7. Duncan JM, Chang C. Nonlinear analysis of stress and strain in soils". J Soil Mech Found Div. 1970;96(SM5):1629-54

8. Vakili KN, Barciago T, Lavason AA, Schanz JA. practical approach to constitutive models for the analysis of geotechnical problems. In: 3rd international conference on computational geomechanics (ComGeo III) 2013.
9. Zevenbergen C, Veerbeek W, Gersonius B, Van Herk S. Challenges in urban flood management: travelling across spatial and temporal scales. J Flood Risk Manag. 2008;1(2):81-8.

10. El-boshy B, Kanae S, Gamaleldin M, Ayad H, Osaragi T, Elbakri W. A framework for pluvial food risk assessment in Alexandria considering the coping capacity. Environ Syst Decis. 2019;39:77-94. https://doi.org/10. 1007/s10669-018-9684-7.

11. World Bank. Egypt overview. Countries. http://www.worldbank.org/en/ country/egypt/overview\#1.https://climateknowledgeportal.worldbank. org/country/egypt. May 30, 2021.

12. Zevenbergen C, Bhattacharya B, Wahaab RA, Elbarki WAI, Busker T, Rodriguez CSA. In the aftermath of the October 2015 Alexandria Flood Challenges of an Arab city to deal with extreme rainfall Storms. Nat Hazards. 2017;86:901-17. https://doi.org/10.1007/s11069-016-2724-z.

13. USAID report. Climate Change information fact sheet, Egypt. September 2015.

14. Dorte V, Robert W, Clemens B, Perrihan A, Richard R, Manfred W, Jakob K, Viviane C, Tamara L, Ferhat E, Philippe R. Tunisia in a changing climate. Assessment and actions for increased resilience and development. Washington DC: The World Bank; 2013.

15. Omran F, El-Sayed M. Vulnerability risk assessment and adaptation to climate change induced sea level rise along the Mediterranean coast of Egypt. Mitig Adapt Strateg Glob Change. 2013;2013(18):1215-37.

16. Galassi G, Spada G. Sea-level rise in the Mediterranean Sea by 2050: Roles of terrestrial ice melt, steric effects and glacial isostatic adjustment. Globa Planet Change. 2014;123(2014):55-66.

17. El-Nahry AH, Doluschitz R. Climate change and its impacts on the coastal zone of the Nile Delta. Egypt Environ Earth Sci. 2010;2010(59):1497-506.

18. El-Ganzori A, Elshamy ME, Hassan M. Towards a climate change adaptation strategy for the water sector in Egypt. Cairo: UNESCO Cairo Office; 2012.

19. Hemeda S, Pitlakis K. Serapeum temple and the ancient annex daughter library in Alexandria, Egypt: geotechnical-geophysical investigations and stability analysis under static and seismic conditions. Eng Geol. 2010;113:33-43.

20. Hemeda S. Geo-environmental monitoring and 3D finite elements stability analysis for site investigation of underground monuments. Horemheb tomb (KV57), Luxor, Egypt. Herit Sci. 2021;9:17. https://doi.org/10.1186/ s40494-021-00487-3.

21. Hemeda S, Sonbol A. Sustainability problems of the Giza pyramids. Herit Sci. 2020;8:8.

22. Hemeda S, Pitilakis I, Papyiani I. Underground monuments (Catacombs) in Alexandria, Egypt. In: 4th international conference on earthquake geotechnical engineering June 25-28, 2007.

23. Hemeda S. Seismic Response Analysis and Protection of Underground Monumental Structures, The Catacombs of Kom ELShoqafa, Alexandria, Egypt. In book: Advances in Geotechnical Earthquake Engineering - Soil Liquefaction and Seismic Safety of Dams and Monuments, IntechOpen; 2012.

24. Sadarangani F, Shehab E, Jones M. Kom El-Shuqafa ground water lowering project, Final Report: Archaeological Assessment Report (Investigations and Findings). January 31, 2019. CDM Smith. USAID Egypt; 2019.

\section{Publisher's Note}

Springer Nature remains neutral with regard to jurisdictional claims in published maps and institutional affiliations. 